SOCIOECONOMIC STATUS AND ADOLESCENT ALCOHOL INVOLVEMENT: EVIDENCE FOR A GENE-ENVIRONMENT INTERACTION

A Thesis
presented to
the Faculty of the Graduate School
at the University of Missouri-Columbia
In Partial Fulfillment
of the Requirements for the Degree
Master of Arts
CHRISTAL N. DAVIS
Dr. Wendy Slutske, Thesis Supervisor

DECEMBER 2017 
The undersigned, appointed by the dean of the Graduate School, have examined the thesis entitled

SOCIOECONOMIC STATUS AND ADOLESCENT ALCOHOL INVOLVEMENT: EVIDENCE FOR A GENE-ENVIRONMENT INTERACTION

presented by Christal Davis, a candidate for the degree of master of psychology, and hereby certify that, in their opinion, it is worthy of acceptance.

Professor Wendy S. Slutske

Professor Phillip K. Wood

Professor Sara Gable 


\section{Acknowledgments}

I would like to thank my advisor, Dr. Wendy S. Slutske, for her dedication to this project and more generally for giving me every opportunity to be successful in the program thus far. It has truly been an honor and a privilege to work with her.

I would also like to thank the other members of my committee, Drs. Phillip K. Wood and Sara Gable, for their thoughtful comments and feedback on this work. 


\section{TABLE OF CONTENTS}

ACKNOWLEDGEMENTS ................................................................................ ii

LIST OF TABLES AND FIGURES...................................................................... iv

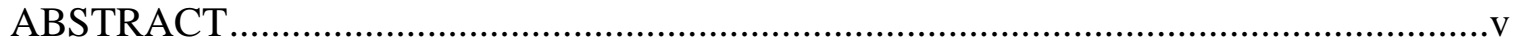

Chapters

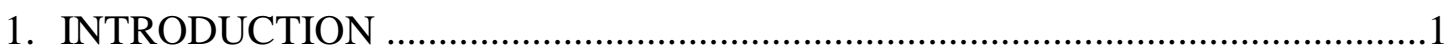

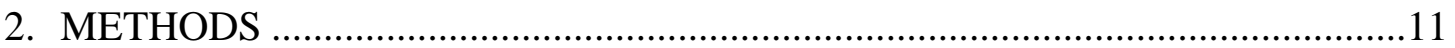

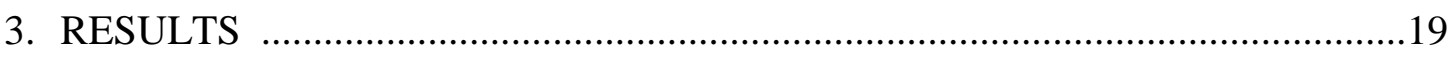

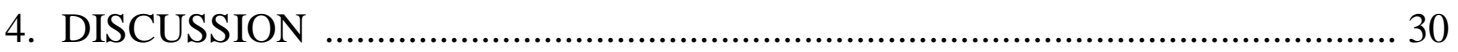

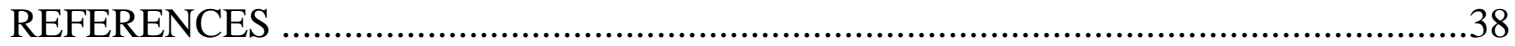

APPENDIX

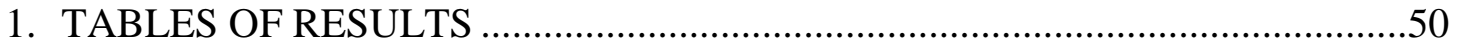

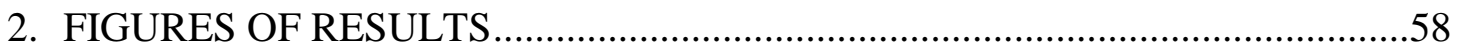

3. SUMMARY OF MODELS TESTED ..............................................................69 


\section{List of Tables and Figures}

Table

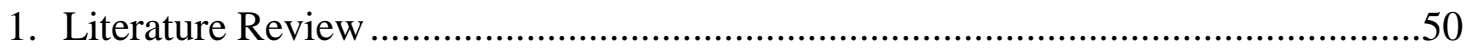

2. Alcohol Composite Prevalence Rates \& Factor Analysis .....................................51

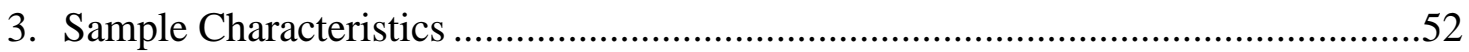

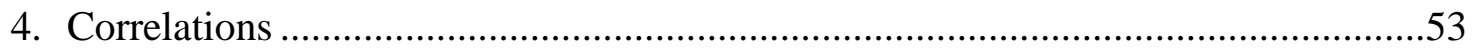

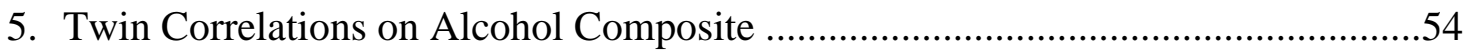

6. Sex Specific Twin Correlations on Alcohol Composite ......................................55

7. Full Sample Unstandardized Estimates of the Proportion of Variance ....................56

8. Sex Specific Unstandardized Estimates of the Proportion of Variance ...................57

Figure

1. Distribution of Alcohol Composite Scores ......................................................58

2. Distribution of Parental Education Variables.....................................................59

3. Distribution of Maternal and Paternal Education.............................................60

4. Distribution of Family Income .................................................................61

5. Path Diagram for Moderation Models ............................................................62

6. Full Sample GxE Model for Average Parental Education ...................................63

7. Full Sample GxE Model for Highest Parental Education ....................................64

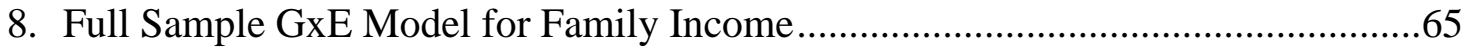

9. Sex Specific GxE Model for Average Parental Education.....................................66

10. Sex Specific GxE Model for Highest Parental Education...................................67

11. Sex Specific GxE Model for Family Income ....................................................68 


\title{
SOCIOECONOMIC STATUS AND ADOLESCENT ALCOHOL INVOLVEMENT: EVIDENCE FOR A GENE-ENVIRONMENT INTERACTION
}

\author{
Christal N. Davis \\ Dr. Wendy Slutske, Thesis Supervisor
}

\begin{abstract}
Adolescent alcohol use patterns stem from both genetic and environmental influences. In addition to these factors contributing additively to risk for use, genetic and environmental factors interact with each other to inhibit or exacerbate risk (Young-Wolff et al., 2011). Socioeconomic status (SES) is one environmental factor that might interact with genetic risk for alcohol use. Two theories exist for understanding how SES might interact with genetic risk: 1) the social control model (Shanahan \& Hofer, 2005) and 2) the diathesis stress model (South et al., 2015). The current study examined indicators of both family social status and financial resources as potential moderators of genetic and environmental influences on alcohol involvement among adolescents using data from the 1962 National Merit Twin Study. Results provided evidence for moderation of genetic and environmental influences on alcohol involvement by family income, with increased genetic contributions to alcohol involvement among individuals with lower family incomes and increased environmental contributions to alcohol use among those with higher family incomes. Despite a lack of significance, analyses did show that genetic and shared environmental influences varied across average parental education levels, particularly for females. These findings suggest etiological influences on alcohol involvement vary as a function of an adolescent's socioeconomic status. Implications and limitations are discussed.
\end{abstract}




\section{Introduction}

Among adolescents, alcohol is the most widely used substance, with about threequarters of high school juniors (75.3\%) endorsing lifetime use of alcohol, while almost half $(42.7 \%)$ of high school juniors endorsed past month alcohol use (Eaton et al., 2012). The National Survey on Drug Use and Health (NSDUH) found that almost a fifth $(15.3 \%)$ of 17 -year-olds engaged in past month binge drinking (Center for Behavioral Health Statistics and Quality, 2016). Research also shows that alcohol use tends to peak in late adolescence or early adulthood and then decline thereafter (Chen \& Jacobson, 2013). Alcohol use in adolescence is associated with many negative consequences, including higher risk of an alcohol use disorder and risky sexual behaviors (Dawson et al., 2008; Stueve \& O’Donnell, 2005). Alcohol consumption has also been found to be a predictor of violent offending among adolescent males (Welte \& Wieczorek, 1999). Due to these negative outcomes associated with adolescent alcohol use, a greater understanding of the contributors to use is needed to inform intervention and policy efforts at both the individual and community level.

Prior research shows that an individual's alcohol use is determined by a variety of factors, both environmental and genetic (Polderman et al., 2015; Seglem et al., 2016; Verhulst et al., 2015). This is evidenced by a recently published meta-analysis of twin studies of alcohol-use-related phenotypes in adolescents. This meta-analysis found estimated genetic contributions of $40 \%$ and shared environmental influences of $41 \%$, with the remainder of variance in adolescent alcohol use being attributed to unique environmental influences (Polderman et al., 2015). Research also shows that environmental contributions have the largest impact on alcohol use in adolescence (Dick, 
2011; Polderman et al., 2015; Rose et al., 2001a), suggesting this is an optimal time for examining these factors and their relationship with genetic risk.

\section{The Debated Relationship between SES and Alcohol Use}

Individual and family level socioeconomic status (SES), as well as neighborhood level indicators of disadvantage, have been studied as environmental factors that may be related to alcohol use among adolescents. Some hypotheses, such as the social disorganization theory, suggest that poverty and neighborhood disadvantage should be associated with negative outcomes, including increased rates of alcohol involvement (Bursik, 1988; Shaw \& McKay, 1942). However, findings in this area are often inconsistent with this hypothesis. Research examining disadvantage at the neighborhood level often finds that the most disadvantaged areas have the lowest levels of alcohol use or the highest percentage of abstainers (Browning, 2012; Slutske et al., 2016). Other research has found that neighborhood disadvantage is not related to adolescent alcohol use after considering other factors, such as maternal support and peer alcohol use (Brenner et al., 2011).

Even when individual level SES is considered rather than neighborhood disadvantage, a recent meta-analysis found that most studies also find no relationship between SES and alcohol use in adolescence (Hanson \& Chen, 2007). An earlier metaanalysis of longitudinal studies examining the relationship between childhood SES and later alcohol use also found little evidence to support an association between disadvantage and later alcohol use or abuse (Wiles et al., 2007). Some research even finds that higher socioeconomic status is related to a greater incidence of alcohol use (Melotti et al., 2012; Keyes \& Hasin, 2008; Grittner et al., 2013). However, despite this 
positive association of SES with alcohol consumption, research is conflicting on the association between SES and problematic alcohol use (Grittner et al., 2013; Melotti et al., 2012). An international study examining levels of alcohol consumption and individual SES found that lower SES was associated with an increased risk of problematic drinking behavior among females in high-income and high-income disparity countries like the United States (Grittner et al., 2013). On the other hand, research examining the relationship between children's socioeconomic status early in life and later alcohol use in adolescence found that higher household income was associated with an increased risk of problematic alcohol use, particularly among females (Melotti et al., 2012). Levels of income disparity might help explain why researchers sometimes find moderation of IQ by socioeconomic status in the United States but not in other countries (Hanscombe et al., 2012, Tucker-Drob \& Bates, 2016, Turkheimer et al., 2003). This distinction may be important for understanding differential effects of SES on phenotypes such as alcohol use as well.

When indicators of family social status, such as parental education, are used instead of financial resources indicators, a negative association between SES and alcohol use is more likely to be found, suggesting that adolescents with parents lower in social status might have increased levels of alcohol use (Hanson \& Chen, 2007). For example, research on adolescents in the United Kingdom found that while higher family income was associated with a increased likelihood of having consumed alcohol in the past six months, a higher maternal educational attainment was associated with a decreased risk of binge drinking (Melotti et al., 2011). Research has also shown that adolescents whose parents experience downward socioeconomic mobility, are more likely to endorse past 
year drinking than those children who experienced upward mobility or who retained their disadvantaged status throughout adolescence (Poonawalla et al., 2014). These findings are consistent with other research that shows lower SES is linked to poorer health outcomes and negative health behaviors (Cohen et al., 2013; Goodman, 1999; Link \& Phelan, 1995). These findings suggest the importance of understanding parental level indicators of SES in addition to neighborhood level disadvantage, as family SES might have greater implications for adolescents' alcohol use. Greater attention should be paid to understanding these factors that might increase vulnerability to substance use among lowincome groups.

\section{Does SES Moderate Genetic Risk for Alcohol Use?}

While research shows that genetic and environmental factors, like family level SES, are important additive contributors to alcohol use behavior among adolescents, the two factors may also interact, creating a heightened or decreased susceptibility to alcohol use. A gene-environment interaction $(\mathrm{Gx} \mathrm{E})$ is a phenomenon whereby a protective or risk factor has a greater or lesser impact on a phenotype depending on the individual's genetic vulnerability (Young-Wolff et al., 2011). Gene-environment interactions suggest that environmental contexts can either inhibit or exacerbate an individual's genetic vulnerability for a trait. Some environmental factors, like socioeconomic disadvantage, may act to limit the genetic variability in a trait by imposing a restricted environment that overwhelms genetic predispositions (Bronfenbrenner \& Ceci, 1994; Kendler et al., 2012). The social control model (Shanahan \& Hofer, 2005), which is similar to the bioecological model (Bronfenbrenner \& Ceci, 1994), would align with this idea, suggesting that greater genetic influences would be seen in less stressful or less restricted environments that 
allow for variability in genetic predisposition to be expressed. Socioeconomically disadvantaged environments would act to decrease the heritability of the trait and increase the contribution of the shared environment to variance in alcohol use.

A competing theory, however, would suggest the opposite should be found. The diathesis stress model (South et al., 2015) suggests that a stressful environment would trigger a predisposition for alcohol use. This theory would be supported through a finding of enhanced genetic influences in more stressful or high-risk environments, such as low SES environments (South et al., 2015; Vendlinski et al., 2011). The diathesis stress model suggests that genetic effects do not present themselves until the environment is more permissive or conducive to alcohol use (Vendlinski et al., 2011). These two competing models provide a framework for understanding how environments might interact with risk to provide protection or to elicit greater susceptibility.

\section{Educational Attainment as a Moderator of Risk}

Several studies have started to examine these theories in relation to whether genetic and environmental contributions to alcohol use vary as a function of an individual's education level, which is often used as an indicator of SES. Using the National Longitudinal Study of Adolescent Health (Add Health) data on adolescents followed into young adulthood, Timberlake and colleagues (2007) found a higher genetic contribution to college students' quantity of alcohol use compared to noncollege peers. These findings could be seen as providing support for the diathesis stress model, as a college environment is a stressful environment that seems to trigger genetic risk for alcohol use among students. However, college education could also be viewed as a 
permissive environment that encourages alcohol use and allows genetic predispositions to alcohol use to emerge, consistent with the social control model.

More recent research has found that educational attainment did not moderate genetic risk, but rather interacted with environmental factors, such that a larger proportion of variance in intoxication frequency in those with low education was explained by the environment compared to those with higher educational attainment (Barr et al., 2016). This finding provides some support for the social control model, as it suggests that the environment accounts for a larger proportion of variance in those with lower educational attainment. However, this study only provides limited support, as it did not find moderation of genetic risk, which remained constant across all educational attainment levels (Barr et al., 2016). These findings are similar to those from an earlier study that found moderation of unique environmental influences on alcohol problems, such that those with higher education levels had decreased unique environmental contributions to variance (Latvala et al., 2011a). The study also found moderation of shared environmental and unique environmental influences on the maximum number of drinks in a day. The study found a decreased contribution of the unique environment among those with higher education and a curvilinear effect on the shared environmental influences, such that there was a higher contribution of the shared environment among those with high and low levels of education, but a decreased contribution among those at the mean of education (Latvala et al., 2011a). These findings provide additional evidence for the social control model; however, these studies were conducted using young adult samples, and young adults might have different etiological influences on their alcohol use than adolescents. 
A study among younger adolescents in ninth through eleventh grade found additive genetic influences accounted for significantly less variance in alcohol use among high achieving adolescents (Benner et al., 2014). The results showed that high academic achievement acted as a protective factor against use by moderating the heritability of alcohol consumption (Benner et al., 2014). This suggests that academic achievement may act to restrict genetic variance in alcohol use, as posited by the social control model (Shanahan \& Hofer, 2005).

\section{Toward a Broader Conceptualization of SES}

Prior work examining the relationship between SES and genetic and environmental factors and its impact on alcohol use has often focused on a narrow understanding of SES. Indeed, in the literature in general, SES has often been poorly conceptualized (Kaplan, 1999; Oakes \& Rossi, 2003; Rose et al., 2001b; Shavers, 2007), and there are numerous methodological issues related to the typical measures. For example, while current income is useful for understanding a person's resources and access to goods or services that might promote health, this measure is limited in that it is not useful for understanding adolescent health (Shavers, 2007). Occupation, which has been examined in some prior research (Tuvblad et al, 2006), has its own issues, as minorities or women in the same occupation as white males might have fewer opportunities, lower status, or lower income (Shavers, 2007). This measure, too, is limited in that adolescents' occupations, if they have one, are likely not an accurate assessment of their SES. Because of these issues with conceptualizing adolescent SES, some researchers have called for the need to include multiple measures of SES in adolescent health surveys (Currie et al., 1997). 
Because of these measurement problems, operationalizing socioeconomic status more broadly is of interest, as education alone does not fully capture an individual or family's social status. Research using data from Swedish adolescents examined both parental education and occupational status, which ranged from an unskilled worker to a self-employed professional, higher civil servant, or executive, as potential moderators of the genetic influence on antisocial behavior, which was conceptualized to include substance use (Tuvblad et al., 2016). The researchers found that genetic influences on antisocial behavior were greater for male adolescents in more socioeconomically advantaged families, though this interaction was only found for occupational status and not for parental education level (Tuvblad et al., 2006). Among girls, no moderation was found for either SES indicator (Tuvblad et al., 2006). This finding that occupational status, but not parental education level, moderated genetic influences for males suggests that important information might be lost when SES is narrowly defined.

One recent study has examined alcohol use more specifically and is of interest given its similar conceptualization of SES as the current study. Using a sample of twins ranging from young adults to older adults (ages 25-74), Hamdi and colleagues (2015) examined an individual's household income and educational attainment as moderators of the genetic and environmental influences on amount of alcohol used, frequency of use, and problematic use. Findings showed that genetic influences on amount of alcohol used were greater for those with lower SES, while environmental influences were heightened for those with higher SES (Hamdi et al., 2015). This pattern of results was obtained for both educational attainment and income. Other indicators of alcohol involvement, the frequency of use and problematic use measures, were not moderated by SES. These 
findings are more in line with the diathesis stress model of gene-environment interactions, though Hamdi and colleagues (2015) point out that the positive correlation found in this study between SES and amount of alcohol used would not be expected under the diathesis stress model.

\section{Current Study}

The current project aimed to build upon the prior studies (see Table 1; a list of all tables and figures is provided on page 2) by examining social status and financial indicators of family SES (family income and parental educational attainment) as moderators of genetic and environmental influences on alcohol use among adolescents using the 1962 National Merit Scholarship Qualifying Test (NMSQT) twin sample. While one study examined these two components of SES as moderators of the genetic and environmental influences on alcohol use, this was done in a sample of adults with a wide range of ages and also used an individual's own level of SES, rather than their family of origin's SES (Hamdi et al., 2015). Other studies have typically only examined indicators of education (Benner et al., 2014; Latvala et al., 2011b; Timberlake et al., 2007), which does not fully capture an individual or family's SES. Furthermore, as research suggests the environment has a greater impact on behavioral phenotypes among adolescents compared to adults (Dick, 2011; Polderman et al., 2015; Rose et al., 2001a), examining the impact of these indicators of SES on alcohol use in adolescence is especially important. In addition, this project will shed light on the two competing theories regarding SES's role in alcohol use: the diathesis stress model, which suggests that a stressful environment would trigger genetic predisposition to alcohol use, and the 
social control model, which suggests that a more restricted environment would suppress genetic predisposition to alcohol use.

In our prior research using the 1962 NMSQT twin sample, we found that differences in family SES did not explain the rural moderation of genetic influences on alcohol use among adolescent females (Davis et al., 2017). While those in rural areas were more disadvantaged than those in urban areas, having significantly lower family incomes than their urban peers, significant differences in the heritability of alcohol involvement among rural and urban females could not be explained by SES gap between the groups (Davis et al., 2017). Despite not mediating this gene-environment interaction, SES might act as a significant moderator of genetic or environmental influences on alcohol use in the absence of the examination of rural residency as a moderator. 


\section{Methods}

\section{Participants}

The sample consisted of same-sex twin pairs who completed the 1962 National Merit Scholarship Qualifying Test (NMSQT), a test that is largely taken by college bound high school students (Loehlin \& Nichols, 1976). Twin pairs were identified from 596,241 high school juniors who completed the NMSQT. 1,507 same-sex twin pairs were recruited to respond to a questionnaire; of these, 1,188 (79\%) completed the questionnaire. Among the respondents were 509 monozygotic (MZ) twin pairs (MZF = 293 and $\mathrm{MZM}=216)$ and 330 dizygotic (DZ) twin pairs $(\mathrm{DZF}=195$ and $\mathrm{DZM}=135)$. Participants completed a variety of questions regarding their personality, behavior, and alcohol involvement, in addition to the NMSQT itself. Participants were approximately 17 years old at the time of the NMSQT administration, and the sample was overwhelmingly (98\%) Caucasian, with females being slightly over-represented (58.2\%) as well. In addition to the twins' participation, a parent, stepparent, or guardian of the twin pair provided information pertaining to the twins' family environment while growing up. In almost all cases (92.9\%), the twins' mother completed the parent questionnaire. The father completed the questionnaire in most other instances $(5.6 \%)$, with the remainder of questionnaires completed by a stepparent (.2\%), guardian (.4\%), or another person responsible for care of the children (other; $.8 \%$ ).

\section{Measures}

The measure of alcohol involvement was obtained from the twin questionnaire, while information on family income and parental education was gathered in the parent questionnaire. 
Alcohol involvement. Ten items from the twin questionnaire pertained to drinking behaviors. Eight of these items came from the Objective Behavior Inventory (OBI) and two were from the California Psychological Inventory (CPI). Response options were coded dichotomously, such that 'not at all' was coded as ' 0 ', and 'frequently' or 'occasionally' was coded as a ' 1 '. The percentage of participants who endorsed each item is reported in Table 2. As the alcohol involvement items included a variety of both normative (drank beer) and problem drinking behaviors (drank before breakfast), exploratory and confirmatory factor analyses were conducted to assess whether items could be summed. Exploratory factor analysis in Mplus (Muthen \& Muthen, 2010) suggested that a single factor was the most parsimonious factor structure of the data. Confirmatory factor analysis was conducted in Mplus to account for the clustering of the twin data and to obtain the standardized factor loadings reported in Table 2. Following these analyses, the ten items were summed to obtain an alcohol composite score (Cronbach's $\alpha=0.79$ ). The alcohol composite scores were pro-rated to account for missing items, and the resulting scores were log transformed. After log transformation, the skewness and kurtosis for the full sample were 1.09 and 0.39 , respectively. Prior research has shown evidence that log-transformation of a non-normally distributed phenotype in GxE research limits false positive findings (Murray et al., 2016). The distribution of the alcohol composite variable prior to and following log transformation is presented in Figure 1.

The alcohol composite measure used was similar to the measure reported in Loehlin (2010), except that the three items that were not directly related to the participants' own alcohol use were not included in analyses. The three excluded items 
were: "Women should not be allowed to drink in cocktail bars," "I would disapprove of anyone's drinking to the point of intoxication at a party," and "I have mixed a cocktail consisting of three or more ingredients." The first two items were excluded as they reflected perceptions of alcohol use, rather than actual alcohol involvement, and the third item was excluded since mixing a cocktail does not directly indicate alcohol use by the respondent.

Parental education. Parental education level was assessed with the following item: "What is each parent's highest educational attainment?". This information was obtained separately for both the mother and father's education level. Response options ranged from ' 8 th grade or less' to 'graduate or professional degree beyond the bachelor's degree' (see Table 3). To create a single parental education variable, the average of the mother and father's reported educational attainment was calculated. If information on only one parent's education level was provided, that parent's information was used for the parental education variable. To provide context, in 1962, the median educational attainment was less than a high school diploma (11.4 years of schooling) among those 25 and older (U.S. Department of Commerce, 1963b). A little over a quarter (28.3\%) of those 25 and older had completed high school, while $9.1 \%$ had completed some college, $5.9 \%$ had completed a four-year degree, and 3.1\% had some post-baccalaureate education (U.S. Department of Commerce, 1963b). The sample contains more highly educated individuals than was the norm at the time. The distribution of the average parental education variable is shown in Figure 2. Figure 3 presents the distribution for maternal and paternal education. 
Highest parental education. A highest parental education variable was created by using the highest level of education completed by either the mother or father. About a quarter of the sample (25.4\%) had parents whose highest educational attainment was a high school diploma, while another quarter of participants $(26.2 \%)$ had parents whose highest educational attainment was some college or junior college. Only $12.4 \%$ of the sample had parents whose highest education level was less than a high school diploma. Complete prevalence rates are reported in Table 3. The distribution of the highest parental education variable is shown in Figure 2.

Family income. Family income was assessed in the parent questionnaire by asking, "What is the family's income before taxes?". Response options ranged from 'less than $\$ 5,000$ per year' to ' $\$ 25,000$ and over' (see Table 3). Slightly more than one-tenth $(11 \%)$ of the sample reported incomes below $\$ 5,000$, while almost a quarter $(23.8 \%)$ reported incomes in the range of $\$ 5,000$ to $\$ 7,499$. The distribution of the family income variable is shown in Figure 4. For context, at the time of data collection in 1962, the average family income was $\$ 6,000$ (U.S. Department of Commerce, 1963a). While the U.S. Department of Commerce (1963) reported that at the time of data collection, 39\% of families had incomes over $\$ 7,000$, over half (62.5\%) of the current sample had incomes at or above $\$ 7,500$ suggesting high SES families were overrepresented in the data. Parental education and family income were significantly correlated in our sample $(r=.53$; see Table 4).

\section{Data Analysis}

Descriptive analyses were conducted using SPSS (v23.0; IBM Corp., 2015). These descriptive analyses included prevalence rates on the alcohol composite measure, 
family income, and parental education variables. Correlations between parental education, maternal education, paternal education, family income, and alcohol involvement were calculated (see Table 4).

Power analyses were conducted using the OpenMx 2 (Boker et al., 2011; Neale et al., 2015) and umx packages (Bates et al., 2016b) within the statistical program $\mathrm{R}$ (R Development Core Team, 2013) to determine the study's ability to detect a moderation effect for the genetic component of variance in alcohol involvement. Researchers have called for the need to conduct power analyses in order to aid in the interpretation of findings from gene-environment interaction studies (Hanscombe et al., 2012; Salvatore et al., 2017; van der Sluis et al., 2012). Power analyses were conducted using estimates of small and large moderation effects, as reported by Bates and colleagues (2016a). As sample sizes were different for analyses examining average parental education as a moderator and family income as a moderator due to missing data, power analyses were conducted separately for each.

Structural equation modeling was conducted to determine the proportions of the variance in alcohol involvement accounted for by additive genetic influences (A), shared environmental influences (C), and unique environmental influences (E; see Figure 5). As shown in Figure 5, correlations between additive genetic influences were set to 1.0 for MZ twins and 0.5 for DZ. As shared environmental influences are those aspects of the environment twins share, these correlations were set to 1.0 for both MZ and DZ twins. Unique environmental influences were uncorrelated for both MZ and DZ twins. Evidence for a gene-environment interaction would be shown by significant moderation $\left(\beta_{\mathrm{a}}, \beta_{\mathrm{c}}\right.$, and $\beta_{\mathrm{e}}$ in Figure 5) of parental education and/or family income (SES in Figure 5) on estimates 
of additive genetic, shared environmental, or unique environmental influences. Models were fit examining average parental education, highest parental education, and family income as moderators of genetic and environmental influences on alcohol use. To rule out gene-environment correlation, we regressed out variance in alcohol involvement that is due to family income or average parental education, depending on the model (Purcell, 2001). This removed any potential genetic effects shared between alcohol involvement and income/average parental education (Purcell, 2002). Models were fit allowing MZ and DZ twins' regression weights of alcohol involvement on SES to differ. This extended univariate moderation model decreases the possibility of a false positive finding (van der Sluis et al., 2012). Additionally, analyses were conducted using both the untransformed alcohol composite variable and the log-transformed alcohol composite variable.

Initial models were fit using the full sample and controlling for the effect of sex in order to have maximal power to detect moderation of genetic and environmental influences. These full sample models were fit for the average parental education, highest parental education, maternal education, paternal education, and annual family income moderation models. Additionally, Wald tests were conducted in these full sample analyses to determine whether moderation parameters were significant. Following the analysis of the full sample models, further models were fit to examine whether estimates differed for males and females. Wald tests were conducted in the sex-specific analyses as well to test whether moderation parameters were equal to zero among males and/or among females.

Due to scarcity at the upper and lower ends of the distribution of family income and average parental education, models were also conducted combining some of these 
upper and lower levels. Analyses were conducted using a 4, 5, and the original 6 level parental education moderator variable and a log-transformed and non-transformed alcohol composite outcome variable. For family income, analyses were conducted using a 5, 6, and the original 7 level family income moderator variable and a log-transformed and non-transformed alcohol composite outcome variable (see Appendix). These analyses were conducted to ensure findings were consistent across various conceptualizations of the moderator variables, as well as to ensure that moderation effects were not the result of transformation of the alcohol composite score.

\section{Power Analyses}

Power analyses were conducted to determine the ability of the study to detect moderation of the genetic component of variance. Data was simulated with a shared environment component of .3 and a small unique environmental component (.1), similar to the process undertaken by Bates et al. (2016a). A shared environmental component was included unlike Bates et al. (2016a) procedure, as the shared environment would be expected to contribute to alcohol use among adolescents. All power analyses consisted of 1000 simulations, with the p-value set at .05 . Power to detect a small moderation effect and large moderation effect was calculated using the sex-specific sample sizes for both average parental education and family income, as sample sizes differed due to missing data. A small moderation effect was defined as the genetic component ranging from 0.43 to 0.57 , while a large moderation effect was defined as the genetic component ranging from 0.3 to 0.7 (Bates et al., 2016a).

Parental education. Among males, power to detect a small moderation of genetic component of variance was poor (6.7\%). Power to detect a large effect was similarly low 
$(23.2 \%)$. For females, the study was similarly underpowered, with power of just $8.8 \%$ to detect a small effect and power of $30 \%$ to detect a large effect. Using the full sample size improved power to detect moderation but the analyses were still underpowered, with power of $9.2 \%$ to detect a small effect and power of $47.9 \%$ to detect a large moderation effect.

Family income. Power to detect a small moderation by family income of the genetic component of variance among males was very poor $(7.4 \%)$. The power to detect a large moderation effect among males was just $22.6 \%$. For females, the study was similarly underpowered to detect small (7.7\%) and large (27\%) moderation effects. Using the full sample with males and females combined improved power a bit but analyses were still underpowered to detect moderation, with power of $10.8 \%$ to detect a small moderation effect and power of $45.3 \%$ to detect a large moderation effect. 


\section{Results}

\section{Descriptive Statistics}

The prevalence rates of the alcohol use behaviors are reported in Table 2. Almost two-thirds of participants (61.4\%) reported some alcohol use. However, due concerns about a lack of power, those participants who endorsed no alcohol use were still included in subsequent analyses. An extreme groups analysis revealed twin pairs whose families were in the lowest and highest income groups had significantly different levels of alcohol involvement $(t(262)=-2.155, \mathrm{p}=.032)$, with those twins whose family income was in the highest category (> $\$ 25,000 /$ year) reporting significantly more alcohol involvement than those twins whose family income was in the lowest category $(<\$ 5,000 /$ year $)$. This difference in alcohol involvement by income was not significant when conducting a median split analysis comparing those who reported family incomes less than $\$ 10,000$ to those who reported incomes above this level $(t(1552)=1.591, \mathrm{p}=.112)$. Additionally, those who reported average parental education levels of at least a completed high school education did not significantly differ in alcohol involvement from those who reported average parental education levels below a high school education $(t(1674)=-0.559, \mathrm{p}=$ .576). Maternal and paternal education were significantly correlated in the sample $(r=$ $0.56, p<.0001 ;$ see Table 4).

In the full sample, among those at the lowest levels of average parental education, MZ twin correlations were greater than DZ twin correlations (see Table 5). This suggests the importance of genetic influences on alcohol use among this group. This was a fairly consistent pattern across all parental education levels, with the exception of those whose parents' average educational attainment was a graduate or professional degree. Among 
this group, the DZ twin correlation was much greater than the MZ twin correlation. Full sample twin correlations on the alcohol composite variable within highest parental education levels showed a consistent pattern of greater MZ twin correlations than DZ twin correlations (see Table 5). This was the case for all levels of highest parental education, except for twins whose parents' highest level of education was some high school $(\mathrm{rMZ}=.73$ vs rDZ $=.83)$. Among family income levels, $\mathrm{MZ}$ twin correlations on the alcohol composite were typically greater than DZ twin correlations, with two exceptions: twins whose family incomes were between $\$ 7,500$ and $\$ 9,999$, and twins whose families earned between $\$ 20,000$ and $\$ 24,999$ annually. As average family incomes at the time of data collection were around $\$ 6,000$ a year, each of these groups represented relatively high earning families. In order to explore these patterns further, we conducted more rigorous model fitting analyses. For a summary of all models tested, see Appendix 1.

\section{Full Sample G x E Models}

Among the full sample, phenotypic variance in adolescent alcohol involvement was highest among those individuals with the highest family incomes $\left(s^{2}=.028\right.$ vs. .020 at the lowest levels of income) and among those individuals who had the lowest average parental education levels $\left(\mathrm{s}^{2}=.024 \mathrm{vs} . .015\right.$ at the highest levels of parental education). These variance differences were not significant. Variance differences were examined, as these set the stage for examining differences in genetic and environmental influences. If overall variance is larger in one group, then the genetic, shared, or unique environmental influences (or some combination of the three components) will be larger compared to the other group. 
Parental education. All full sample analyses controlled for the participant's sex, as sex was significantly correlated with alcohol involvement $(r=-.37 ; \mathrm{p}=.005)$. Analyses on average parental education moderation were based on 822 twin pairs $(M Z=$ 498 and DZ = 324). Despite the increased power of the full sample, the findings suggested no evidence of moderation of genetic or environmental influences on alcohol involvement by parental education. An omnibus Wald test of the moderation parameters was not significant $\left(\chi^{2}=0.42, \mathrm{df}=3, \mathrm{p}=0.94\right)$. Wald tests of the moderation of specific A, C, or E parameters were not conducted.

Figure 6 presents a graphical depiction of the change in ACE components of variance across levels of average parental education based on the moderation model. For additional reference, Table 7 presents the unstandardized estimates of the proportion of variance in alcohol involvement attributed to A, C, and E components for the full sample at each level of average parental education. In this combined sample, all components of variance remained relatively stable across the levels of average parental education. It is important to note, however, that this lack of change in variance across levels of average parental education may be due to conflicting moderation patterns found for males and females in the sex-specific moderation model.

Maternal and paternal education levels were also examined separately as moderators of the genetic and environmental influences on alcohol involvement. An omnibus Wald test revealed no evidence of moderation by maternal or paternal education among the full sample (maternal education: $\chi^{2}=0.74, \mathrm{df}=3, \mathrm{p}=0.86$; paternal education: $\left.\chi^{2}=0.53, \mathrm{df}=3, \mathrm{p}=0.91\right)$. While there was no evidence of significant moderation, genetic influences appeared to increase as maternal education increased 
( $26.5 \%$ to $39 \%$ ), with shared environmental influences decreasing ( $46.1 \%$ to $29.9 \%$ ), and the unique environmental influences remained relatively stable as maternal education levels increased $(27.4 \%$ to $31.1 \%)$. Results for paternal education were similarly nonsignificant, but patterns of genetic and shared environmental influences differed from those of maternal education. Genetic influences appeared to decrease as paternal education increased (39.4\% to $26.1 \%$ ), shared environmental influences increased $(33.4 \%$ to $43.2 \%$ ), and unique environmental influences remained stable across paternal education increased $(27.3 \%$ to $30.7 \%)$.

Highest parental education. Findings suggested no evidence of moderation of genetic or environmental influences on alcohol involvement by highest parental education attainment. An omnibus Wald test of the moderation parameters was not significant $\left(\chi^{2}=0.65, \mathrm{df}=3, \mathrm{p}=0.89\right)$. As a result of the lack of a significant omnibus test, Wald tests of the moderation of specific A, C, or E parameters were not conducted. While results were nonsignificant, Figure 7 presents a graphical depiction of the change in ACE components of variance across levels of highest parental education based on the moderation model. Additionally, Table 7 presents unstandardized estimates of the proportion of variance in alcohol involvement attributed to A, C, and E components for the full sample at each level of highest parental education attainment. In the full sample, the additive genetic component appeared to increase as the level of highest parental education increased, with additive genetic factors accounting for less than a quarter of variance $(23.2 \%)$ among participants with parents at the lowest levels of education and $39 \%$ of variance among participants with parents at the highest levels of education. The shared environmental component accounted for the most variance in those with the 
lowest levels of parental education, accounting for almost half the variance $(48.6 \%)$ in alcohol involvement among twins whose parents' highest level of education is $8^{\text {th }}$ grade or less. For twins whose parents' highest level of educational attainment is a graduate or professional degree, shared environmental components accounted for less than a third of variance in alcohol involvement $(31.5 \%)$.

Family income. An omnibus Wald test of the moderation parameters was significant $\left(\chi^{2}=21.86, \mathrm{df}=3, \mathrm{p}<0.0001\right)$. Wald tests of the individual parameters of moderation were conducted, with moderation of genetic $\left(\chi^{2}=5.97, \mathrm{df}=1, \mathrm{p}=.01\right)$, shared environmental $\left(\chi^{2}=6.98, \mathrm{df}=1, \mathrm{p}=.01\right)$, and unique environmental influences all reaching significance $\left(\chi^{2}=6.57, \mathrm{df}=1, \mathrm{p}=.01\right)$.

Figure 8 presents a graphical depiction of the significant change in ACE components of variance across levels of annual family income for the combined sample full moderation model. Among those at the lowest level of family income, genetic factors accounted for half of the variance in alcohol involvement, while for those adolescents whose families had the highest level of income (greater than $\$ 25,000$ ), genetic factors accounted for virtually none $(2 \%)$ of the variance in alcohol involvement. The shared environmental component accounted for approximately a fourth $(26 \%)$ of the variance in alcohol involvement at the lowest level of family income, while at the highest level of annual family income, the environment accounted for about two-thirds (67\%) of the variance in adolescent alcohol involvement. The unique environmental component remained relatively stable across levels of family income, ranging from accounting for a quarter of the variance at the lowest levels of income to a little under a third (31\%) of the variance at the highest level of income. Table 7 presents unstandardized estimates of the 
proportion of variance in alcohol involvement attributed to A, C, and E components for the full sample at each level of annual family income.

\section{Sex-Specific G x E Models}

Parental education. Due to sparsity within cells at the highest level of average parental education (0 MZ males, $6 \mathrm{MZ}$ females, $5 \mathrm{DZ}$ males, and $5 \mathrm{DZ}$ females), the categories of "college graduate" and "graduate/professional degree" were combined for sex-specific analyses. The findings suggested no evidence of moderation of genetic or environmental influences on alcohol involvement by average parental education. An omnibus Wald test of all moderation parameters was not significant $\left(\chi^{2}=4.79\right.$, $\mathrm{df}=6, \mathrm{p}=$ 0.57). Omnibus Wald tests of moderation for males and females were also not significant (males: $\chi^{2}=2.20, \mathrm{df}=3, \mathrm{p}=.53$; females: $\chi^{2}=2.59, \mathrm{df}=3, \mathrm{p}=.46$ ). As a result of the lack of a significant omnibus test of moderation, Wald tests of the moderation of specific A, C, or E parameters were not conducted.

Figure 9 presents a graphical depiction of the change in ACE components of variance across levels of average parental education from the sex-specific full moderation model. While no significant moderation was present, the results from the $\mathrm{G} \times \mathrm{E}$ model for females followed the pattern that would be expected by the social control model, as females whose parents had low education levels had the lowest genetic contribution to alcohol use. At the lowest levels of average parental education, the additive genetic component accounted for $10.9 \%$ of variance in alcohol involvement among females, while at the highest levels of parental education, the genetic component accounted for half of the variance $(50.0 \%)$ in alcohol involvement. On the other hand, males whose parents had low education levels had the highest genetic contribution to use. The genetic 
component accounted for $38.7 \%$ of the variance in alcohol involvement among males whose parents had the lowest levels of education, while additive genetic influences accounted for about a third of variance $(30.2 \%)$ in alcohol involvement among males whose parents had the highest levels of education. For further reference, unstandardized estimates of the proportion of variance in alcohol involvement attributed to A, C, and E components for males and females at each level of average parental education are presented in Table 8 .

When examining maternal education separately as a moderator of the genetic and environmental influences on alcohol involvement, results were similar to those found for average parental education. An omnibus Wald test of all moderation parameters was not significant $\left(\chi^{2}=3.25, \mathrm{df}=6, \mathrm{p}=.78\right)$. Omnibus Wald tests of moderation for males and females were also not significant (males: $\chi^{2}=1.45, \mathrm{df}=3, \mathrm{p}=.69$; females: $\chi^{2}=1.80$, df $=3, \mathrm{p}=.62$ ). Among females, a similar pattern to that of average parental education was found, whereby there were decreased genetic contributions at lower levels of maternal education and higher shared environmental contributions at lower levels of maternal education. At the lowest levels of maternal education, additive genetic influences accounted for just $18.8 \%$ of the variance in alcohol involvement, while at the highest levels of maternal education these factors accounted for almost half of variance (44.9\%) in alcohol involvement. For males, the opposite pattern was found, similar to the results for the average parental education variable. At the lowest levels of maternal education, additive genetic influences accounted for almost half of the variance (44.2\%) in alcohol involvement, while at the highest levels of maternal education, additive genetic 
influences accounted for just under a quarter of the variance $(24.1 \%)$ in alcohol involvement.

Results for paternal education also showed the same pattern as the findings for average parental education. An omnibus Wald test of all moderation parameters did not show evidence for moderation by paternal education $\left(\chi^{2}=2.66, \mathrm{df}=6, \mathrm{p}=.85\right)$. An omnibus Wald test for moderation among females was not significant $\left(\chi^{2}=1.29, \mathrm{df}=3, \mathrm{p}\right.$ $=.73$ ). Among females, additive genetic factors accounted for the least amount of variance (18.6\%) among those with the lowest levels of paternal education and the largest amount of variance $(50.5 \%)$ among those with the highest levels of paternal education. Shared environmental influences followed the opposite pattern, with these factors accounting for over half of the variance $(54.7 \%)$ in alcohol involvement among those with the lowest levels of paternal education. At the highest levels of paternal education, shared environmental factors accounted for just $21.7 \%$ of the variance in alcohol involvement. An omnibus Wald test for moderation among males was also not significant $\left(\chi^{2}=1.37, \mathrm{df}=3, \mathrm{p}=.71\right)$. Among males, additive genetic influences accounted for approximately half of the variance $(50.1 \%)$ in alcohol involvement among those with the lowest levels of paternal education. At the highest levels of paternal education, genetic influences accounted for just $13.2 \%$ of the variance in alcohol involvement. Shared environmental factors accounted for just under a quarter of the variance $(24.1 \%)$ in alcohol involvement among males with the lowest levels of paternal education. At the highest levels of paternal education, shared environmental influences accounted for almost half $(54 \%)$ of the variance in alcohol involvement. However, none of the ACE 
components showed evidence for significant moderation by maternal or paternal education levels.

Highest parental education. An omnibus Wald test of all moderation parameters was not significant $\left(\chi^{2}=1.91, \mathrm{df}=6, \mathrm{p}=.93\right)$. An omnibus Wald test of moderation among males was nonsignificant $\left(\chi^{2}=0.57, \mathrm{df}=3, \mathrm{p}=0.90\right)$, as was an omnibus Wald test of moderation among females $\left(\chi^{2}=1.34, \mathrm{df}=3, \mathrm{p}=.72\right)$. Wald tests of the moderation of specific A, C, or E parameters were not conducted due to the lack of a significant omnibus test of moderation.

Figure 10 presents a graphical depiction of the nonsignificant change in the ACE components of variance across levels of highest parental education for both females and males, respectively. Among females, additive genetic influences accounted for the smallest share of variance (12.4\%) among those whose parents had lower education levels. At the highest levels of parental education, genetic influences accounted for almost half of the variance $(48.2 \%)$ in alcohol involvement among females. Shared environmental influences followed the opposite pattern, with these factors accounting for over half of the variance $(59.3 \%)$ in alcohol involvement among those whose parents' highest education level was an $8^{\text {th }}$ grade education or less. Females whose parents' highest education level was a graduate or professional degree, shared environmental factors accounted for just a quarter (25.4\%) of variance in alcohol involvement. Among males, A, C, and E components remained relatively stable across all levels of highest parental education.

Family income. Due to sparsity within sex-specific groups at the highest level of family income (3 MZ males, $21 \mathrm{MZ}$ females, $5 \mathrm{DZ}$ males, and $11 \mathrm{DZ}$ females), the top 
two levels of family income were combined for sex-specific analyses. An omnibus Wald test of all the moderation parameters in the sex-specific analyses was not significant $\left(\chi^{2}=\right.$ 4.18, $\mathrm{df}=6, \mathrm{p}=0.65)$. Omnibus Wald tests of moderation for males and females were similarly nonsignificant (males: $\chi^{2}=0.23, \mathrm{df}=3, \mathrm{p}=0.97$; females: $\chi^{2}=3.95$, df $=3, \mathrm{p}=$ 0.27). As a result of the lack of any significant omnibus test of moderation, Wald tests of the moderation of specific A, C, or E parameters were not conducted. Results for the full seven level family income variable were also nonsignificant (see Appendix 1).

Figure 11 presents a graphical depiction of the nonsignificant change in ACE components of variance across levels of annual family income for the sex-specific full moderation model. For females, the additive genetic component decreased as levels of family income increased. The additive genetic component in females accounted for approximately two-fifths $(41.9 \%)$ of the variance in alcohol involvement at the lowest levels of family income and just over one-fifth (23\%) of the variance in alcohol involvement at the highest levels of income. The shared environmental component accounted for $22.2 \%$ of the variance in alcohol involvement at the lowest levels of family income and over half $(55.2 \%)$ of the variance in alcohol involvement at the highest levels of family income. The unique environmental component accounted for just over a third (35.9\%) of variance in alcohol involvement among females whose family incomes were less than $\$ 5,000$ a year, while among females with family incomes $\$ 20,000$ and over, the unique environment accounted for slightly more than a fifth $(21.8 \%)$ of variance in alcohol involvement.

Results for males followed a similar pattern as those for females. The additive genetic component for males in families with the lowest annual incomes accounted for 
over a third (36\%) of the variance in alcohol involvement. Among those males with family incomes of at least $\$ 20,000$, the additive genetic component accounted for just $14.2 \%$ of the variance in alcohol involvement. The shared environmental component, on the other hand, increased along with family income, with the shared environment accounting for just over a quarter $(28.5 \%)$ of the variance in alcohol involvement among males with the lowest annual family incomes and approximately half (51.9\%) of the variance in those with the highest annual family incomes. Despite the similar patterns of change in both males and females, there was no significant moderation. For further reference, unstandardized estimates of the proportion of variance in alcohol involvement attributed to A, C, and E components for males and females at each level of family income are presented in Table 8. 


\section{Discussion}

This study examined whether indicators of SES moderated genetic and environmental influences on alcohol involvement among adolescents. There was no evidence of significant moderation by average parental education levels among the full sample or sex-specific analyses. However, among the sex-specific samples, there did appear to be moderation effects, particularly among females, that the study may have simply been underpowered to detect. Among females, genetic influences on alcohol involvement increased as average parental education levels increased, while shared environmental influences decreased as average parental education levels increased. This pattern of moderation is in line with the social control model and is consistent with many of the prior studies examining education as a moderator of genetic influences on alcohol use (Barr et al., 2016; Latvala et al., 2011a; Timberlake et al., 2007). Among males, the opposite moderation pattern emerged. For males, genetic influences on alcohol involvement decreased as average parental education levels increased, and shared environmental influences increased. This finding is more in line with recent work by Hamdi and colleagues (2015) and provides some support for the diathesis stress model. As the pattern of effects for males and females were in the opposite direction, combining the two groups in the full sample analyses may have canceled out the moderation effects and led to the nonsignificant results that showed etiological influences remained constant across average parental education levels.

This different pattern of moderation effects for males and females might suggest that at least some aspects of socioeconomic status have a differential impact on etiologic influences for males and females. It might be that among males, a low SES environment 
provided additional stress and pressure that triggered a genetic diathesis to alcohol use, while among females, a low SES environment might have acted as a particularly conservative and restricting one in which the opportunity to engage in alcohol use is limited. Prior research with this sample examining the impact of rural residency on etiologic influences on alcohol involvement found evidence for the social control model only among women, while among men there was no moderation effect of rural residency (Davis et al., 2017). This might suggest that females living in low income and/or rural environments were subjected to particularly restrictive monitoring on alcohol use behaviors at the time of data collection.

Maternal and paternal education levels were examined separately as moderators of alcohol involvement, as prior research often highlights the importance of maternal education, in particular, for child and adolescent health and academic performance (Carneiro et al., 2012; Güneş, 2015). Among the full sample and sex-specific analyses, there was no evidence of significant moderation of the ACE components by either maternal or paternal education. The nonsignificant moderation by maternal and paternal education levels showed similar patterns of as that of the average parental education variable. The pattern among males fit more closely with the diathesis stress model (decreasing genetic contribution as education increased and increased shared environmental contribution as education increased), while the pattern among females adhered more closely to the social control model (increasing genetic contributions to variance as education increased and decreased shared environmental contributions as education increased). 
Similar to average parental education and the individual parental education variables, there was no evidence of significant moderation using the highest parental education variable. Among the full sample, there was a small change in heritability across highest parental education levels. As highest parental education levels increased, heritability showed a small increase, with shared environmental contributions decreasing across levels of highest parental education. This provides a bit of support for the social control model, and these effects were primarily found among females, as A, C, and E components remained relatively stable across all levels of highest parental education for males. None of the indicators of parental education tested showed evidence of significance moderation, perhaps suggesting that education was not an important environmental moderator at the time of data collection.

Unlike the various parental education measures, evidence of significant moderation by annual family income was found among the full sample analysis, with genetic influences on alcohol involvement decreasing and shared environmental influences increasing as family income increased. Unique environmental influences contributed slightly more to alcohol involvement as family incomes increased. This pattern of decreasing genetic influences and increasing shared environmental influences across family income levels was also found in the sex-specific analyses, with results for both males and females showing similar patterns. Despite the significance among the full sample, the sex-specific analyses showed no evidence of significant moderation by family income. It is also important to note that only the full seven level conceptualization of family income resulted in significant moderation. Combining levels of family income, particularly among lower income groups, might have reduced some of the important 
variability among groups and led to the lack of significant findings. Additionally, the lack of significant moderation in the sex-specific analyses might be due to a lack of power, as power analyses showed the study was significantly underpowered to detect even a large moderation effect among these restricted samples. The significant moderation finding provides support for the diathesis stress model, similar to results by Hamdi and colleagues (2015), suggesting that a low income environment activates genetic predispositions to alcohol use among adolescents, while a high income environment might protect against genetic predispositions to use.

The moderation effects of family income on genetic and environmental influences on alcohol involvement were somewhat consistent with the diathesis stress model. This model would posit that genetic influences on alcohol involvement would be greater in a high-risk environment, such as a low SES environment (Vendlinski et al., 2011). However, this model would also predict a negative association between SES and alcohol involvement, while our study found a small positive association between family income and alcohol involvement. This is consistent with similar work in the area, which has also found greater genetic influences on alcohol use in lower SES environments and a small positive association between alcohol use and SES (Hamdi et al., 2015). However, these moderation effects that are in line with the diathesis stress model are inconsistent with many prior studies that examined education only as a moderator of genetic and environmental influences on alcohol use (Barr et al., 2016; Latvala et al., 2011a; Timberlake et al., 2007). These findings might suggest that income and educational attainment have different patterns of moderation of ACE components on alcohol use. 


\section{Limitations and Future Extensions}

Although the use of data from 1962 United States provided a test of the moderation of genetic influences on alcohol use by SES in a novel context, the age of these data were also limiting in a number of ways. The changes that have occurred in America since these data were collected might reduce generalizability to today's adolescents, who may face substantially different environments or restrictions on alcohol use as a result of their parent's socioeconomic status. For example, in the decades since these data were collected, income inequality in the United States and many other nations has grown, and this may have important implications for understanding the impact of socioeconomic status on genetic and environmental factors related to alcohol use (Cingano, 2014). Research suggests that income inequality at both the national and neighborhood level is associated with increased frequency of alcohol use (Galea et al., 2007), increased quantity of alcohol consumption (Elgar et al., 2005), and increased risk of death from alcohol related illnesses (Dietze et al., 2009). Income inequality might act to increase the importance of a family's socioeconomic status as a moderator of genetic and environmental influences on alcohol use. Furthermore, some studies have shown that SES moderates genetic influences on IQ primarily in higher income nations that also have high degrees of income disparity (Tucker-Drob \& Bates, 2016).

Our sample is limited in that it primarily consisted of high-achieving, white adolescents. It is important to note that in 1960, around the time of data collection, more than a quarter of individuals (27.2\%) dropped out of high school (Snyder et al., 2016). Twins taking the NMSQT would have been those who had not dropped out of high school and who were likely planning on attending college. Given that the data consisted 
of more affluent individuals or those who were likely on upwardly mobile trajectories, this may limit the generalizability of the $\mathrm{G} x \mathrm{E}$ findings to other groups. Additionally, those of other races/ethnicities may show different patterns of $\mathrm{G} \times \mathrm{E}$ that cannot be captured by this study. This problem of limited ethnic and racial diversity is not unique to the current study; many human genetics and genomic studies lack sufficient numbers of minorities and many scientists have called for greater inclusion in this area (Bustamante et al., 2011; Need \& Goldstein, 2009). Future studies should seek to include minorities and those of diverse backgrounds in order to spread the benefits of genetics research to a wider group of individuals.

Another limitation of the current study is the use of an alcohol composite measure. Although used in previous studies (LeGrand et al, 2008; Loehlin, 2010; Polderman et al., 2015), such a measure does not provide information about specific alcohol behaviors like quantity or frequency of use among adolescents. Prior research has found that SES has different moderation effects on various aspects of alcohol use (Hamdi et al., 2015), and the study's use of an alcohol composite measure did not allow us to detect such effects. Instead, this study captured general adolescent alcohol use across a variety of dimensions. Prior research has also shown that different indicators of SES might have different relationships to various alcohol use behaviors (Casswell et al., 2003; Huckle et al., 2010); using an alcohol composite measure did not allow us to investigate whether parental education and income had the same relationship with various alcohol outcomes.

The alcohol composite measure was also limited in that most participants had low levels of involvement, and many items were endorsed infrequently (see Table 2). While it 
would have been ideal to include in analyses only those participants who endorsed alcohol involvement, this study did not have sufficient power to include only those twins who were alcohol involved. Power analyses revealed that even splitting the participants into sex-specific groups led to the study being significantly underpowered. Therefore, while analyses are limited by the inclusion of those with no alcohol involvement, the study would not have been feasible otherwise.

While multiple measures of SES were included in this study in an attempt to present a broader conceptualization of SES than prior studies, it is important to note that these measures might have had very different impacts on social status and economic opportunities at the time of data collection, particularly for women and minorities (Shavers, 2007). For example, education and income correlations have been found to differ by race and ethnicity (Braveman et al., 2001). These issues in conceptualizing SES continue to be important for those who study the impact of SES on various health outcomes. Further, educational level at the time of data collection likely led to very different occupational and earning outcomes than the same level of education would today (Krieger et al., 1997; Levy \& Murnane, 1992). In order to have the broadest index of family SES, including the occupational status of the parents would have been ideal, but this information was not available.

It is also important to note that family income significantly moderated genetic and environmental influences on adolescent alcohol involvement only when the full seven level conceptualization of family income was used. Using the six or five level income variables that combined either the top or top and bottom levels of income did not result in significant moderation when using the log-transformed alcohol composite. This might 
due to the fact that combining levels reduced important variability between levels and impacted the ability to see moderation effects. Using the untransformed alcohol composite variable yielded significant results for both the full seven level and six level income variables.

Future studies of socioeconomic status as a moderator of genetic and environmental influences on alcohol use among adolescents should examine and compare the impact of family social status and family financial resources on alcohol use. Some researchers (Hanson \& Chen, 2007) have also proposed examining peer social status as a moderator of genetic influences on alcohol use, as this might be a more important indicator of status among adolescents. In addition, studies examining this moderating effect should make use of more specific alcohol outcome measures, like quantity and frequency of use, in order to detect precise effects of the moderator on alcohol involvement. Future studies might also examine how income disparity at both the neighborhood level and country level might impact findings of moderation by SES on genetic and environmental influences on alcohol use. 


\section{References}

Barr, P. B., Salvatore, J. E., Maes, H., Aliev, F., Latvala, A., Viken, R., ... \& Dick, D. M. (2016). Education and alcohol use: A study of gene-environment interaction in young adulthood. Social Science \& Medicine, 162, 158-167. doi:10.1016/j.socscimed.2016.06.031

Bates, T. C., Hansell, N. K., Martin, N. G., \& Wright, M. J. (2016a). When does socioeconomic status (SES) moderate the heritability of IQ? No evidence for $\mathrm{g} \times$ SES interaction for IQ in a representative sample of 1176 Australian adolescent twin pairs. Intelligence, 56, 10-15. doi:10.1016/j.intell.2016.02.003

Bates, T. C., Neale, M. C., \& Maes, H. H. (2016b). Umx: A library for Structural Equation and Twin Modelling in R. Journal of Statistical Software (Retrieved from https://github.com/tbates/umx, under review).

Benner, A. D., Kretsch, N., Harden, K. P., \& Crosnoe, R. (2014). Academic achievement as a moderator of genetic influences on alcohol use in adolescence. Developmental psychology, 50(4), 1170. doi:10.1037/a0035227

Boker, S., Neale, M., Maes, H., Wilde, M., Spiegel, M., Brick, T., ... \& Mehta, P. (2011). OpenMx: an open source extended structural equation modeling framework. Psychometrika, 76(2), 306-317. doi:10.1007/s11336-010-9200-6

Braveman, P., Cubbin, C., Marchi, K., Egerter, S., \& Chavez, G. (2001). Measuring socioeconomic status/position in studies of racial/ethnic disparities: maternal and infant health. Public Health Reports, 116(5), 449-463. doi:10.1016/s00333549(04)50073-0 
Brenner, A. B., Bauermeister, J. A., \& Zimmerman, M. A. (2011). Neighborhood variation in adolescent alcohol use: Examination of socioecological and social disorganization theories. Journal of Studies on Alcohol and Drugs, 72(4), 651659. doi:10.15288/jsad.2011.72.651

Bronfenbrenner, U., \& Ceci, S. J. (1994). Nature-nurture reconceptualized in developmental perspective: A bioecological model. Psychological Review, 101(4), 568-586. doi:10.1037/0033-295x.101.4.568

Browning, S. E. (2012). Neighborhood, school, and family effects on the frequency of alcohol use among Toronto youth. Substance Use \& Misuse, 47(1), 31-43. doi:10.3109/10826084.2011.625070

Bursik, R. J. (1988). Social disorganization and theories of crime and delinquency: Problems and prospects. Criminology, 26(4), 519-552. doi:10.1111/j.17459125.1988.tb00854.x

Bustamante, C. D., Francisco, M., \& Burchard, E. G. (2011). Genomics for the world. Nature, 475(7355), 163-165. doi:10.1038/475163a

Carneiro, P., Meghir, C., \& Parey, M. (2013). Maternal education, home environments, and the development of children and adolescents. Journal of the European Economic Association, 11(suppl_1), 123-160. doi:10.1111/j.15424774.2012.01096.x

Casswell, S., Pledger, M., \& Hooper, R. (2003). Socioeconomic status and drinking patterns in young adults. Addiction, 98(5), 601-610. doi:10.1046/j.13600443.2003.00331.x 
Center for Behavioral Health Statistics and Quality. (2016). 2015 National Survey on Drug Use and Health: Detailed Tables. Substance Abuse and Mental Health Services Administration, Rockville, MD.

Chen, P., \& Jacobson, K. C. (2012). Developmental trajectories of substance use from early adolescence to young adulthood: Gender and racial/ethnic differences. Journal of Adolescent Health, 50(2), 154-163. doi:10.1016/j.jadohealth.2011.05.013

Cingano, F. (2014). Trends in Income Inequality and its Impact on Economic Growth. OECD Social, Employment and Migration Working Papers. doi:10.1787/5jxrjncwxv6j-en

Cohen, A. K., Rehkopf, D. H., Deardorff, J., \& Abrams, B. (2013). Education and obesity at age 40 among American adults. Social Science \& Medicine, 78, 34-41. doi:10.1016/j.socscimed.2012.11.025

Currie, C. E., Elton, R. A., Todd, J., \& Platt, S. (1997). Indicators of socioeconomic status for adolescents: the WHO Health Behaviour in School-aged Children Survey. Health Education Research, 12(3), 385-397. doi:10.1093/her/12.3.385

Davis, C. N., Natta, S. S., \& Slutske, W. S. (2017). Moderation of Genetic Influences on Alcohol Involvement by Rural Residency among Adolescents: Results from the 1962 National Merit Twin Study. Behavior Genetics, 1-9. doi:10.1007/s10519017-9867-x

Dawson, D. A., Goldstein, R. B., Patricia Chou, S., June Ruan, W., \& Grant, B. F. (2008). Age at first drink and the first incidence of adult-onset DSM-IV alcohol 
use disorders. Alcoholism: Clinical and Experimental Research, 32(12), 2149-

2160. doi:10.1111/j.1530-0277.2008.00806.x

Dick, D. M. (2011). Developmental changes in genetic influences on alcohol use and dependence. Child Development Perspectives, 5(4), 223-230. doi:10.1111/j.17508606.2011.00207.x

Dietze, P. M., Jolley, D. J., Chikritzhs, T. N., Clemens, S., Catalano, P., \& Stockwell, T. (2009). Income inequality and alcohol attributable harm in Australia. BMC Public Health, 9(1). doi:10.1186/1471-2458-9-70

Eaton, D. K., Kann, L., Kinchen, S., Shanklin, S., Flint, K. H., Hawkins, J., ... \& Whittle, L. (2012). Youth risk behavior surveillance-United States, 2011. Morbidity and Mortality Weekly Report. Surveillance Summaries (Washington, DC: 2002), 61(4), 1-162.

Elgar, F. J. (2005). Income inequality and alcohol use: a multilevel analysis of drinking and drunkenness in adolescents in 34 countries. The European Journal of Public Health, 15(3), 245-250. doi:10.1093/eurpub/cki093

Galea, S., Ahern, J., Tracy, M., \& Vlahov, D. (2007). Neighborhood Income and Income Distribution and the Use of Cigarettes, Alcohol, and Marijuana. American Journal of Preventive Medicine, 32(6), S195-S202. doi:10.1016/j.amepre.2007.04.003

Goodman, E. (1999). The role of socioeconomic status gradients in explaining differences in US adolescents' health. American Journal of Public Health, 89(10), 1522-1528.

Grittner, U., Kuntsche, S., Gmel, G., \& Bloomfield, K. (2012). Alcohol consumption and social inequality at the individual and country levels - results from an 
international study. European Journal of Public Health, 23(2), 332-339.

doi:10.1093/eurpub/cks044

Güneş, P. M. (2015). The role of maternal education in child health: Evidence from a compulsory schooling law. Economics of Education Review, 47, 1-16. doi:10.1016/j.econedurev.2015.02.008

Hamdi, N. R., Krueger, R. F., \& South, S. C. (2015). Socioeconomic status moderates genetic and environmental effects on the amount of alcohol use. Alcoholism: Clinical and Experimental Research, 39(4), 603-610. doi:10.1111/acer.12673

Hanscombe, K. B., Trzaskowski, M., Haworth, C. M., Davis, O. S., Dale, P. S., \& Plomin, R. (2012). Socioeconomic status (SES) and children's intelligence (IQ): In a UK-representative sample SES moderates the environmental, not genetic, effect on IQ. PLoS One, 7(2), e30320. doi:10.1371/journal.pone.0030320

Hanson, M. D., \& Chen, E. (2007). Socioeconomic status and health behaviors in adolescence: a review of the literature. Journal of Behavioral Medicine, 30(3), 263. doi:10.1007/s10865-007-9098-3

Huckle, T., You, R. Q., \& Casswell, S. (2010). Socio-economic status predicts drinking patterns but not alcohol-related consequences independently. Addiction, 105(7), 1192-1202. doi:10.1111/j.1360-0443.2010.02931.x

IBM Corp. Released 2015. IBM SPSS Statistics for Windows, Version 23.0. Armonk, NY: IBM Corp.

Kaplan, G. A. (1999). Part III Summary. Annals of the New York Academy of Sciences, 896(1), 116-119. 
Kendler, K. S., Chen, X., Dick, D., Maes, H., Gillespie, N., Neale, M. C., \& Riley, B. (2012). Recent advances in the genetic epidemiology and molecular genetics of substance use disorders. Nature Neuroscience, 15(2), 181-189. doi:10.1038/nn.3018

Keyes, K. M., \& Hasin, D. S. (2008). Socio-economic status and problem alcohol use: the positive relationship between income and the DSM-IV alcohol abuse diagnosis. Addiction, 103(7), 1120-1130. doi:10.1111/j.1360-0443.2008.02218.x

Krieger, N., Williams, D. R., \& Moss, N. E. (1997). Measuring social class in US public health research: concepts, methodologies, and guidelines. Annual Review of Public Health, 18(1), 341-378. doi:10.1146/annurev.publhealth.18.1.341

Latvala, A., Dick, D. M., Tuulio-Henriksson, A., Suvisaari, J., Viken, R. J., Rose, R. J., \& Kaprio, J. (2011a). Genetic correlation and gene-environment interaction between alcohol problems and educational level in young adulthood. Journal of studies on alcohol and drugs, 72(2), 210-220. doi:10.15288/jsad.2011.72.210

Latvala, A., Tuulio-Henriksson, A., Dick, D. M., Vuoksimaa, E., Viken, R. J., Suvisaari, J., ... \& Rose, R. J. (2011b). Genetic origins of the association between verbal ability and alcohol dependence symptoms in young adulthood. Psychological Medicine, 41(03), 641-651. doi:10.1017/s0033291710001194

Legrand, L. N., Keyes, M., McGue, M., Iacono, W. G., \& Krueger, R. F. (2008). Rural environments reduce the genetic influence on adolescent substance use and rulebreaking behavior. Psychological Medicine, 38(09), 1341-1350. doi:10.1017/s0033291707001596 
Levy, F., \& Murnane, R. J. (1992). US earnings levels and earnings inequality: A review of recent trends and proposed explanations. Journal of Economic Literature, 30(3), 1333-1381.

Link, B. G., \& Phelan, J. (1995). Social conditions as fundamental causes of disease. Journal of Health and Social Behavior, 80-94. doi:10.2307/2626958

Loehlin, J. C. (2010). Is there an active gene-environment correlation in adolescent drinking behavior?. Behavior Genetics, 40(4), 447-451. doi:10.1007/s10519-010$9347-\mathrm{z}$

Loehlin, J. C., \& Nichols, R. C. (1976). Heredity, environment, and personality: A study of 850 sets of twins. University of Texas Press.

Melotti, R., Lewis, G., Hickman, M., Heron, J., Araya, R., \& Macleod, J. (2012). Early life socio-economic position and later alcohol use: birth cohort study. Addiction, 108(3), 516-525. doi:10.1111/add.12018

Melotti, R., Heron, J., Hickman, M., Macleod, J., Araya, R., \& Lewis, G. (2011). Adolescent Alcohol and Tobacco Use and Early Socioeconomic Position: The ALSPAC Birth Cohort. Pediatrics, 127(4), e948-e955. doi:10.1542/peds.20093450

Murray, A. L., Molenaar, D., Johnson, W., \& Krueger, R. F. (2016). Dependence of Gene-by-Environment Interactions (GxE) on Scaling: Comparing the Use of Sum Scores, Transformed Sum Scores and IRT Scores for the Phenotype in Tests of GxE. Behavior genetics, 46(4), 552-572. doi:10.1007/s10519-016-9783-5

Muthen, L. K., \& Muthen B. O. (2010). Mplus. Muthen \& Muthen. 
Neale, M. C., Hunter, M. D., Pritikin, J. N., Zahery, M., Brick, T. R., Kirkpatrick, R. M., ... Boker, S. M. (2015). OpenMx 2.0: Extended Structural Equation and Statistical Modeling. Psychometrika, 81(2), 535-549. doi:10.1007/s11336-014$9435-8$

Need, A. C., \& Goldstein, D. B. (2009). Next generation disparities in human genomics: concerns and remedies. Trends in Genetics, 25(11), 489-494. doi:10.1016/j.tig.2009.09.012

Oakes, J. M., \& Rossi, P. H. (2003). The measurement of SES in health research: current practice and steps toward a new approach. Social Science \& Medicine, 56(4), 769784. doi:10.1016/s0277-9536(02)00073-4

Polderman, T. J., Benyamin, B., De Leeuw, C. A., Sullivan, P. F., Van Bochoven, A., Visscher, P. M., \& Posthuma, D. (2015). Meta-analysis of the heritability of human traits based on fifty years of twin studies. Nature Genetics, 47(7), 702-709. doi:10.1038/ng.3285

Polderman, T. J., Benyamin, B., De Leeuw, C. A., Sullivan, P. F., Van Bochoven, A., Visscher, P. M., \& Posthuma, D. (2015, May 18). MaTCH: Meta-Analysis of Twin Correlations and Heritability. Retrieved from http://match.ctglab.nl/\#/specific/age_groups.

Poonawalla, I. B., Kendzor, D. E., Owen, M. T., \& Caughy, M. O. (2014). Family income trajectory during childhood is associated with adolescent cigarette smoking and alcohol use. Addictive Behaviors, 39(10), 1383-1388.

doi:10.1016/j.addbeh.2014.05.005 
Purcell, S. (2002). Variance components models for gene-environment interaction in twin analysis. Twin Research, 5(06), 554-571. doi:10.1375/twin.5.6.554

R Development Core Team (2013). R: A language and environment for statistical computing. R Foundation for Statistical Computing, Vienna, Austria. ISBN 3900051-07-0, URL http://www.R-project.org.

Rose, R. J., Dick, D. M., Viken, R. J., \& Kaprio, J. (2001a). Gene-Environment Interaction in Patterns of Adolescent Drinking: Regional Residency Moderates Longitudinal Influences on Alcohol Use. Alcoholism: Clinical and Experimental Research, 25(5), 637-643. doi:10.1097/00000374-200105000-00002

Rose, D., Pevalin, D., Elias, P., \& Martin, J. (2001b). Towards a European socioeconomic classification. Final Report to Eurostat of the Expert Group, UK Office for National Statistics.

Salvatore, J. E., Cho, S. B., \& Dick, D. M. (2017). Genes, environments, and sex differences in alcohol research. Journal of Studies on Alcohol and Drugs, 78(4), 494-501. doi:10.15288/jsad.2017.78.494

Seglem, K. B., Waaktaar, T., Ask, H., \& Torgersen, S. (2016). Sex differences in genetic and environmental contributions to alcohol consumption from early adolescence to young adulthood. Addiction, 111(1):1188-1195. doi:10.1111/add.13321

Shanahan, M. J., \& Hofer, S. M. (2005). Social context in gene-environment interactions: Retrospect and prospect. The Journals of Gerontology Series B: Psychological Sciences and Social Sciences, 60(Special Issue 1), 65-76. doi:10.1093/geronb/60.special_issue_1.65 
Shavers, V. L. (2007). Measurement of socioeconomic status in health disparities research. Journal of the National Medical Association, 99(9), 1013.

Shaw, C. R., \& McKay, H. D. (1942). Juvenile delinquency and urban areas: A study of rates of delinquents in relation to differential characteristics of local communities in American cities. Chicago, IL: University of Chicago Press.

Slutske, W. S., Deutsch, A. R., \& Piasecki, T. M. (2016). Neighborhood contextual factors, alcohol use, and alcohol problems in the United States: evidence from a nationally representative study of young adults. Alcoholism: Clinical and Experimental Research, 40(5), 1010-1019. doi:10.1111/acer.13033

Snyder, T. D., de Brey, C., \& Dillow, S. A. (2016). Digest of Education Statistics 2014, NCES 2016-006. National Center for Education Statistics.

South, S. C., Hamdi, N. R., \& Krueger, R. F. (2015). Biometric Modeling of GeneEnvironment Interplay: The Intersection of Theory and Method and Applications for Social Inequality. Journal of Personality. doi:10.1111/jopy.12231

Stueve, A., \& O’Donnell, L. N. (2005). Early alcohol initiation and subsequent sexual and alcohol risk behaviors among urban youths. American Journal of Public Health, 95(5), 887-893. doi:10.2105/ajph.2003.026567

Timberlake, D. S., Hopfer, C. J., Rhee, S. H., Friedman, N. P., Haberstick, B. C., Lessem, J. M., \& Hewitt, J. K. (2007). College attendance and its effect on drinking behaviors in a longitudinal study of adolescents. Alcoholism: Clinical and Experimental Research, 31(6), 1020-1030. doi:10.1111/j.1530-

0277.2007.00383.x 
Tucker-Drob, E. M., \& Bates, T. C. (2016). Large cross-national differences in genex socioeconomic status interaction on intelligence. Psychological science, 27(2), 138-149. doi:10.1177/0956797615612727

Turkheimer, E., Haley, A., Waldron, M., d'Onofrio, B., \& Gottesman, I. I. (2003). Socioeconomic status modifies heritability of IQ in young children. Psychological science, 14(6), 623-628. doi:10.1046/j.0956-7976.2003.psci_1475.x

Tuvblad, C., Grann, M., \& Lichtenstein, P. (2006). Heritability for adolescent antisocial behavior differs with socioeconomic status: gene-environment interaction. Journal of Child Psychology and Psychiatry, 47(7), 734-743. doi:10.1111/j.1469-7610.2005.01552.x

U.S. Department of Commerce, Bureau of the Census. (1963a). Average Family Income Up Four Percent in 1962 [Press release]. Washington, D.C.: Bureau of the Census.

U.S. Department of Commerce, Bureau of the Census (1963b). Educational Attainment: March 1962. Population Characteristics [Press release]. Washington, D.C.: Bureau of the Census.

van der Sluis, S., Posthuma, D., \& Dolan, C. V. (2012). A note on false positives and power in G× E modelling of twin data. Behavior Genetics, 42(1), 170-186. doi:10.1007/s10519-011-9480-3

Vendlinski, M. K., Lemery-Chalfant, K., Essex, M. J., \& Goldsmith, H. H. (2011). Genetic risk by experience interaction for childhood internalizing problems: converging evidence across multiple methods. Journal of Child Psychology and Psychiatry, 52(5), 607-618. doi:10.1111/j.1469-7610.2010.02343.x 
Verhulst, B., Neale, M. C., \& Kendler, K. S. (2015). The heritability of alcohol use disorders: a meta-analysis of twin and adoption studies. Psychological medicine, 45(5), 1061-1072. doi:10.1017/s0033291714002165

Welte, J. W., \& Wieczorek, W. F. (1998). Alcohol, intelligence, and violent crime in young males. Journal of Substance Abuse, 10(3), 309-319. doi:10.1016/s08993289(99)00002-4

Wiles, N. J., Lingford-Hughes, A., Daniel, J., Hickman, M., Farrell, M., Macleod, J., ... \& Lewis, G. (2007). Socio-economic status in childhood and later alcohol use: a systematic review. Addiction, 102(10), 1546-1563. doi:10.1111/j.13600443.2007.01930.x

Young-Wolff, K. C., Enoch, M. A., \& Prescott, C. A. (2011). The influence of geneenvironment interactions on alcohol consumption and alcohol use disorders: A comprehensive review. Clinical Psychology Review, 31(5), 800-816. doi:10.1016/j.cpr.2011.03.005 
SOCIOECONOMIC STATUS AND ALCOHOL INVOLVEMENT

\section{Appendix 1}

\section{Tables of Results}

Table 1.

Studies examining SES as a moderator of genetic and environmental influences on alcohol use

\begin{tabular}{|c|c|c|c|c|c|c|}
\hline Study & $N$ & Location & $\begin{array}{l}\text { Age } \\
\text { Range }\end{array}$ & Alcohol Outcome(s) & SES Measure(s) & Results \\
\hline $\begin{array}{l}\text { Benner et } \\
\text { al. (2014) }\end{array}$ & 399 twin pairs & US & $15-17$ & Ever used alcohol & $\begin{array}{l}\text { Academic } \\
\text { achievement }\end{array}$ & $\begin{array}{l}\text { Genetic influences > among lower achieving } \\
\text { adolescents }\end{array}$ \\
\hline \multirow{3}{*}{$\begin{array}{l}\text { Tuvblad et } \\
\text { al. (2006) }\end{array}$} & \multirow{3}{*}{1133 twin pairs } & \multirow{3}{*}{ Sweden } & \multirow{3}{*}{$16-17$} & \multirow{3}{*}{$\begin{array}{l}\text { Antisocial behavior } \\
\text { (including substance } \\
\text { use) }\end{array}$} & Parental education & No G x E for parental education \\
\hline & & & & & Parental occupation & $\begin{array}{l}\text { Genetic influences > among boys with higher } \\
\text { parental occupation status }\end{array}$ \\
\hline & & & & & Neighborhood SES & $\begin{array}{l}\text { Genetic influences }>\text { among those in } \\
\text { advantaged neighborhoods }\end{array}$ \\
\hline \multirow{2}{*}{$\begin{array}{l}\text { Timberlake } \\
\text { et al. }(2007)\end{array}$} & \multirow{2}{*}{$\begin{array}{l}148 \mathrm{MZ}, 186 \mathrm{DZ} \\
387 \mathrm{FS}, 134 \mathrm{HS}\end{array}$} & \multirow{2}{*}{ US } & \multirow{2}{*}{$18-24$} & Consumption & \multirow{2}{*}{ College attendance } & $\begin{array}{l}\text { Genetic influences on quantity > among college } \\
\text { students compared to non-college peers }\end{array}$ \\
\hline & & & & $\begin{array}{l}\text { Binge drinking } \\
\text { frequency }\end{array}$ & & No GxE with binge drinking \\
\hline \multirow{2}{*}{$\begin{array}{l}\text { Barr et al. } \\
(2016)\end{array}$} & \multirow{2}{*}{3403 twin pairs } & \multirow{2}{*}{ Finland } & \multirow{2}{*}{$19-27$} & Drinking frequency & \multirow{2}{*}{$\begin{array}{l}\text { Educational } \\
\text { attainment }\end{array}$} & \multirow{2}{*}{$\begin{array}{l}\text { Environmental influences }>\text { among those with } \\
\text { lower education }\end{array}$} \\
\hline & & & & $\begin{array}{l}\text { Intoxication } \\
\text { frequency }\end{array}$ & & \\
\hline $\begin{array}{l}\text { Latvala et } \\
\text { al. (2011a) }\end{array}$ & $\begin{array}{l}2414 \text { complete } \\
\text { twin pairs \& } 30 \\
\text { individual twins }\end{array}$ & Finland & $22-28$ & Alcohol problems & $\begin{array}{l}\text { Educational } \\
\text { attainment }\end{array}$ & $\begin{array}{l}\text { Environmental influences }>\text { among those with } \\
\text { lower education }\end{array}$ \\
\hline \multirow{3}{*}{$\begin{array}{l}\text { Hamdi et } \\
\text { al. (2015) }\end{array}$} & \multirow{3}{*}{672 twin pairs } & \multirow{3}{*}{ US } & \multirow{3}{*}{$25-74$} & $\begin{array}{l}\text { Amount of alcohol } \\
\text { used }\end{array}$ & \multirow{3}{*}{$\begin{array}{l}\text { Income } \\
\& \\
\text { Education }\end{array}$} & $\begin{array}{l}\text { Genetic influences on amount used }>\text { among } \\
\text { those with low SES }\end{array}$ \\
\hline & & & & Frequency of use & & No G x E for frequency of use \\
\hline & & & & Alcohol problems & & No G x E for alcohol problems \\
\hline
\end{tabular}


Table 2.

Composite alcohol involvement scale in the 1962 National Merit Twin Study sample

Item

Prevalence

(\%)

I have drunk wine.

I have dr5unk liquor.

I have drunk in a bar.

I have had a hangover.

I have drunk before breakfast.

I have become intoxicated.

I have drunk beer.

I have gone on the wagon.

I have never done any heavy drinking (r).

I have used alcohol excessively.

$\begin{array}{rl}46.5 & .56 \\ 31.9 & .86 \\ 10.0 & .79 \\ 10.0 & .94 \\ 2.8 & .34 \\ 12.4 & .97 \\ 33.9 & .86 \\ 3.6 & .57 \\ 9.9 & .80 \\ 3.9 & .73\end{array}$

Standardized

factor loading

.86

.79

.94

.34

.97

86

57

.73

$\%$ variance explained

Note: $r=$ reverse coded 
Table 3.

Characteristics of the 1962 National Merit Twin Study sample

Family Income

Prevalence

(\%)

$<\$ 5,000$

11.8

$\$ 5,000-7,499$

25.7

$\$ 7,500-9,999$

21.4

$\$ 10,000-14,999$

23.6

$\$ 15,000-19,999$

9.4

$\$ 20,000-24,999$

3.0

$\$ 25,000+$

5.1

Mother's Education

Prevalence

$(\%)$

$8^{\text {th }}$ grade or less

6.6

Part high school

12.8

High school graduate $\quad 37.2$

Part college/junior college $\quad 23.8$

College graduate $\quad 15.1$

Father's Education

Graduate/professional degree

4.5

Prevalence

(\%)

$8^{\text {th }}$ grade or less

11.0

Part high school $\quad 12.0$

High school graduate $\quad 26.0$

Part college/junior college $\quad 21.8$

College graduate $\quad 15.0$

Graduate/professional degree $\quad 14.1$

Highest Parental

Prevalence

Education

$(\%)$

\begin{tabular}{lr}
\hline $8^{\text {th }}$ grade or less & 3.9 \\
Part high school & 8.5 \\
High school graduate & 25.4 \\
Part college/junior college & 26.2 \\
College graduate & 19.5 \\
Graduate/professional degree & 16.5
\end{tabular}


SOCIOECONOMIC STATUS AND ALCOHOL INVOLVEMENT

Table 4

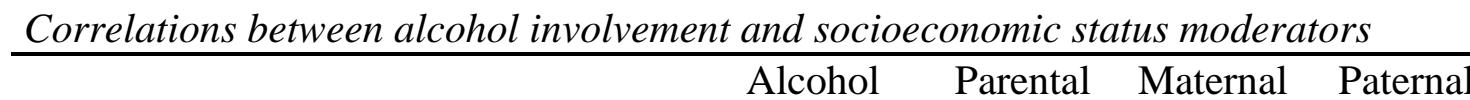
involvement education education education Income

\begin{tabular}{|c|c|c|c|c|c|c|}
\hline $\begin{array}{l}\text { Alcohol } \\
\text { involvement }\end{array}$ & $\begin{array}{l}\text { Correlation } \\
\text { p-value }\end{array}$ & 1 & $\begin{array}{l}.01 \\
.63 \\
\end{array}$ & $\begin{array}{r}-.04 \\
.28 \\
\end{array}$ & $\begin{array}{l}.01 \\
.84 \\
\end{array}$ & $\begin{array}{r}.09 * \\
.02 \\
\end{array}$ \\
\hline Parental education & $\begin{array}{l}\text { Correlation } \\
\text { p-value }\end{array}$ & & 1 & $\begin{array}{r}.86^{* *} \\
.000\end{array}$ & $\begin{array}{r}.91 * * \\
.000\end{array}$ & $\begin{array}{r}.53 * * \\
.000\end{array}$ \\
\hline Maternal educatior & $\begin{array}{l}\text { Correlation } \\
\text { p-value }\end{array}$ & & & 1 & $\begin{array}{r}.56^{* *} \\
.000\end{array}$ & $\begin{array}{r}.41 * * \\
.000\end{array}$ \\
\hline Paternal education & $\begin{array}{l}\text { Correlation } \\
\text { p-value }\end{array}$ & & & & 1 & $\begin{array}{r}.52 * * \\
.000\end{array}$ \\
\hline
\end{tabular}

**. Correlation is significant at the 0.01 level.

*. Correlation is significant at the 0.05 level. 
Table 5.

Twin correlations among the full sample on the log-transformed alcohol composite variable

\begin{tabular}{lll}
\hline \multicolumn{3}{c}{ Average Parental Education } \\
\hline & rMZ $(\mathrm{N})$ & rDZ $(\mathrm{N})$ \\
\cline { 2 - 3 } $8^{\text {th }}$ grade or less & $\mathbf{0 . 7 5}(47)$ & $\mathbf{0 . 7 3}(22)$ \\
Some high school & $\mathbf{0 . 7 4}(86)$ & $\mathbf{0 . 5 2}(54)$ \\
High school graduate & $\mathbf{0 . 6 1}(170)$ & $\mathbf{0 . 6 2}(102)$ \\
Part college/junior college & $\mathbf{0 . 7 3}(107)$ & $\mathbf{0 . 5 6}(82)$ \\
College graduate & $\mathbf{0 . 8 0}(82)$ & $\mathbf{0 . 4 2}(54)$ \\
Graduate/professional degree & $0.20(6)$ & $\mathbf{0 . 6 8}(10)$ \\
\hline \multicolumn{4}{c}{ Family Income } \\
\hline \multicolumn{4}{c}{ rMZ $(\mathrm{N})$} & rDZ $(\mathrm{N})$ \\
\hline \$5,000 & $\mathbf{0 . 6 8}(64)$ & $\mathbf{0 . 4 7}(124)$ \\
\$5,000 - 7,499 & $\mathbf{0 . 6 5}(99)$ & $\mathbf{0 . 5 1}(106)$ \\
\$7,500 - 9,999 & $\mathbf{0 . 6 2}(44)$ & $\mathbf{0 . 7 6}(14)$ \\
\$10,000 - 14,999 & $\mathbf{0 . 7 6}(24)$ & $\mathbf{0 . 5 3}(28)$ \\
\$15,000 - 19,999 & $\mathbf{0 . 6 3}(76)$ & $\mathbf{0 . 4 6}(67)$ \\
\$20,000 - 24,999 & $\mathbf{0 . 7 3}(77)$ & $\mathbf{0 . 8 3}(29)$ \\
\$25,000 + & $\mathbf{0 . 8 0}(9)$ & $\mathbf{0 . 4 9}(16)$ \\
\hline \multicolumn{4}{c}{ Highest Parental Education } \\
\hline \multicolumn{4}{c}{ rMZ $(\mathrm{N})$} & rDZ $(\mathrm{N})$ \\
8 ${ }^{\text {th }}$ grade or less & $\mathbf{0 . 8 5}(22)$ & $\mathbf{0 . 7 2}(10)$ \\
Some high school & $\mathbf{0 . 7 3}(49)$ & $\mathbf{0 . 8 3}(21)$ \\
High school graduate & $\mathbf{0 . 6 4}(132)$ & $\mathbf{0 . 4 8}(77)$ \\
Part college/junior college & $\mathbf{0 . 6 6}(130)$ & $\mathbf{0 . 5 5}(85)$ \\
College graduate & $\mathbf{0 . 7 0}(87)$ & $\mathbf{0 . 6 5}(73)$ \\
Graduate/professional degree & $\mathbf{0 . 7 9}(78)$ & $\mathbf{0 . 3 5}(58)$ \\
\hline Note: Bold type indicates significance. \\
\hline \multicolumn{4}{c}{} \\
\hline
\end{tabular}


Table 6.

Twin correlations on the log-transformed alcohol composite variable for males and females

\begin{tabular}{|c|c|c|c|c|}
\hline \multicolumn{5}{|c|}{ Average Parental Education } \\
\hline & \multicolumn{2}{|c|}{$\mathrm{rMZ}(\mathrm{N})$} & \multicolumn{2}{|c|}{$\mathrm{rDZ}(\mathrm{N})$} \\
\hline & Males & Females & Males & Females \\
\hline $8^{\text {th }}$ grade or less & 0.69 (20) & $\mathbf{0 . 8 0}(27)$ & $0.67(7)$ & $\mathbf{0 . 8 2}(15)$ \\
\hline Part high school & $0.82(35)$ & $0.66(51)$ & $0.44(21)$ & $\mathbf{0 . 5 5}(33)$ \\
\hline High school graduate & $0.57(74)$ & $0.64(96)$ & $\mathbf{0 . 6 0}(47)$ & $0.65(55)$ \\
\hline Some college/junior college & $0.73(48)$ & $0.74(59)$ & $0.64(29)$ & $0.53(53)$ \\
\hline College graduate & $0.79(33)$ & $\mathbf{0 . 8 1}(49)$ & $0.28(24)$ & $\mathbf{0 . 5 9}(30)$ \\
\hline Graduate/professional degree & NA (0) & $0.20(6)$ & $0.95(5)$ & $0.42(5)$ \\
\hline \multicolumn{5}{|c|}{ Family Income } \\
\hline & \multicolumn{2}{|c|}{$\mathrm{rMZ}(\mathrm{N})$} & \multicolumn{2}{|c|}{$\mathrm{rDZ}(\mathrm{N})$} \\
\hline & Males & Females & Males & Females \\
\hline$<\$ 5,000$ & $0.64(31)$ & $0.71(33)$ & $0.40(10)$ & $0.49(18)$ \\
\hline$\$ 5,000-7,499$ & $0.67(54)$ & $\mathbf{0 . 6 1}(70)$ & $0.66(31)$ & $0.36(45)$ \\
\hline$\$ 7,500-9,999$ & $0.58(41)$ & $0.65(58)$ & $0.54(26)$ & $\mathbf{0 . 9 1}(41)$ \\
\hline$\$ 10,000-14,999$ & $0.78(51)$ & $0.72(55)$ & $0.59(38)$ & $\mathbf{0 . 4 4}(39)$ \\
\hline$\$ 15,000-19,999$ & $0.68(18)$ & $0.36(26)$ & $0.19(13)$ & $\mathbf{0 . 6 9}(16)$ \\
\hline$\$ 20,000-24,999$ & $0.68(8)$ & $0.76(8)$ & $1.00(3)$ & $0.78(6)$ \\
\hline$\$ 25,000+$ & $-0.08(3)$ & $\mathbf{0 . 9 0}(21)$ & $0.09(5)$ & $\mathbf{0 . 5 0}(11)$ \\
\hline \multicolumn{5}{|c|}{ Highest Parental Education } \\
\hline & \multicolumn{2}{|c|}{$\mathrm{rMZ}(\mathrm{N})$} & \multicolumn{2}{|c|}{$\mathrm{rDZ}(\mathrm{N})$} \\
\hline & Males & Females & Males & Females \\
\hline $8^{\text {th }}$ grade or less & $0.91(8)$ & $0.72(14)$ & $0.63(4)$ & $\mathbf{0 . 8 2}(6)$ \\
\hline Part high school & $0.71(23)$ & $0.74(26)$ & $\mathbf{0 . 8 6}(10)$ & $\mathbf{0 . 8 0}(11)$ \\
\hline High school graduate & $0.70(54)$ & $0.59(78)$ & $0.17(28)$ & $\mathbf{0 . 6 4}(49)$ \\
\hline Some college/junior college & $0.61(58)$ & $0.71(72)$ & $\mathbf{0 . 6 2}(40)$ & $\mathbf{0 . 3 3}(45)$ \\
\hline College graduate & $0.64(31)$ & $0.78(56)$ & $0.52(24)$ & $0.71(49)$ \\
\hline Graduate/professional degree & $\mathbf{0 . 8 3}(36)$ & $\mathbf{0 . 7 5}(42)$ & $0.39(27)$ & $0.30(31)$ \\
\hline
\end{tabular}


Table 7.

Full sample unstandardized estimates of the portions of variation in the alcohol involvement composite explained by genetic and environmental influences in the 1962 National Merit Twin Study sample

\begin{tabular}{|c|c|c|c|}
\hline \multicolumn{4}{|c|}{ Average Parental Education } \\
\hline & A & $\mathrm{C}$ & $\mathrm{E}$ \\
\hline $8^{\text {th }}$ grade or less & $.81[-.06,1.69]$ & $1.06[.19,1.92]$ & $.71[.49, .93]$ \\
\hline Some high school & $.80[.21,1.40]$ & $1.01[.43,1.50]$ & $.71[.56, .86]$ \\
\hline High school graduate & $.79[.39,1.19]$ & $.97[.58,1.36]$ & $.71[.62, .81]$ \\
\hline Some college & $.78[.38,1.18]$ & $.93[.53,1.33]$ & $.72[.62, .81]$ \\
\hline College graduate & $.77[.18,1.36]$ & $.89[.31,1.47]$ & $.72[.57, .87]$ \\
\hline $\begin{array}{l}\text { Graduate/professional } \\
\text { degree }\end{array}$ & $.76[-.09,1.61]$ & $.85[.03,1.67]$ & $.72[.50, .95]$ \\
\hline
\end{tabular}
degree

Highest Parental Education

\begin{tabular}{|c|c|c|c|}
\hline & A & $\mathrm{C}$ & $\mathrm{E}$ \\
\hline $8^{\text {th }}$ grade or less & $.61[-.22,1.43]$ & $1.27[.30,2.24]$ & $.74[.51, .97]$ \\
\hline Some high school & $.66[.03,1.30]$ & $1.15[.49,1.81]$ & $.73[.56, .90]$ \\
\hline High school graduate & $.72[.27,1.18]$ & $1.04[.61,1.47]$ & $.72[.61, .84]$ \\
\hline Some college & $.79[.42,1.16]$ & $.94[.57,1.30]$ & $.71[.63, .80]$ \\
\hline College graduate & .85 [.38, 1.33] & $.84[.36,1.31]$ & $.71[.59, .82]$ \\
\hline $\begin{array}{l}\text { Graduate/professional } \\
\text { degree }\end{array}$ & $.92[.21,1.63]$ & $.74[.10,1.39]$ & $.70[.53, .87]$ \\
\hline \multicolumn{4}{|c|}{ Family Income } \\
\hline & $\mathrm{A}$ & $\mathrm{C}$ & $\mathrm{E}$ \\
\hline$<\$ 5,000 /$ year & $1.26[.69,1.82]$ & $.64[.08,1.20]$ & $.61[.49, .74]$ \\
\hline$\$ 5,000-7,499 /$ year & $.80[.23,1.36]$ & $.84[.33,1.34]$ & $.68[.57, .78]$ \\
\hline$\$ 7,500-9,999 /$ year & $.44[-.16,1.04]$ & $1.06[.61,1.50]$ & $.74[.64, .84]$ \\
\hline$\$ 10,000-14,999 /$ year & $.19[-.35, .72]$ & $1.30[.90,1.70]$ & $.81[.70, .92]$ \\
\hline$\$ 15,000-19,999 /$ year & $.04[-.28, .37]$ & $1.58[1.15,2.00]$ & $.88[.73,1.03]$ \\
\hline$\$ 20,000-24,999 /$ year & $.001[-.04, .04]$ & $1.88[1.32,2.43]$ & $.95[.75,1.15]$ \\
\hline$\$ 25,000+/$ year & $.06[-.51, .64]$ & $2.20[1.43,2.98]$ & $1.03[.77,1.29]$ \\
\hline
\end{tabular}


Table 8.

Sex-specific unstandardized estimates of the portions of variation in the alcohol involvement composite explained by genetic and environmental influences in the 1962 National Merit Twin Study sample

\begin{tabular}{|c|c|c|c|c|c|c|}
\hline & \multicolumn{3}{|c|}{ Males } & \multicolumn{3}{|c|}{ Females } \\
\hline & A & $\mathrm{C}$ & $\mathrm{E}$ & A & $\mathrm{C}$ & $\mathrm{E}$ \\
\hline \multicolumn{7}{|c|}{ Average Parental Education } \\
\hline $8^{\text {th }}$ grade or less & $1.38[-.37,3.13]$ & $1.17[-.40,2.72]$ & $1.02[.56,1.48]$ & $.21[-.30, .73]$ & $1.20[.46,1.94]$ & $.56[.35, .76]$ \\
\hline Some high school & $1.22[.09,2.36]$ & $1.13[.06,2.21]$ & $.97[.68,1.26]$ & $.37[-.10, .84]$ & $1.00[.55,1.46]$ & $.56[.43, .70]$ \\
\hline High school graduate & $1.07[.30,1.84]$ & $1.10[.35,1.85]$ & $.92[.74,1.10]$ & $.57[.17, .96]$ & $.82[.44,1.20]$ & $.57[.47, .66]$ \\
\hline Some college & $.93[.12,1.75]$ & $1.07[.28,1.87]$ & $.87[.66,1.08]$ & $.81[.33,1.29]$ & $.66[.17,1.15]$ & $.57[.46, .69]$ \\
\hline $\begin{array}{l}\text { Bachelor's degree or } \\
\text { higher }\end{array}$ & $.81[-.31,1.92]$ & $1.04[-.10,2.18]$ & $.82[.50,1.15]$ & $1.09[.27,1.91]$ & $.51[-.12,1.15]$ & $.58[.40, .75]$ \\
\hline \multicolumn{7}{|c|}{ Family Income } \\
\hline$<\$ 5,000 /$ year & $1.28[-.57,3.12]$ & $.86[-.59,2.32]$ & $.90[.59,1.20]$ & $.75[-.63,2.13]$ & $.40[-.56,1.36]$ & $.64[.35, .94]$ \\
\hline$\$ 5,000-7,499 /$ year & $1.07[.02,2.12]$ & $.98[-.05,2.02]$ & $.92[.70,1.13]$ & $.71[-.13,1.55]$ & $.54[-.21,1.30]$ & $.62[.44, .80]$ \\
\hline$\$ 7,500-9,999 /$ year & $.88[.10,1.66]$ & $1.11[.36,1.85]$ & $.94[.75,1.12]$ & $.67[.22,1.12]$ & $.71[.20,1.21]$ & $.49[.60, .70]$ \\
\hline$\$ 10,000-14,999 /$ year & $.71[-.38,1.79]$ & $1.24[.33,2.16]$ & $.96[.71,1.20]$ & $.63[.09,1.17]$ & $.90[.44,1.35]$ & $.57[.44, .70]$ \\
\hline$\$ 15,000-19,999 /$ year & $.55[-.92,2.03]$ & $1.38[-.11,2.87]$ & $.98[.62,1.34]$ & $.59[-.34,1.53]$ & $1.11[.25,1.96]$ & $.55[.33, .77]$ \\
\hline$\$ 20,000+/$ year & $.42[-1.35,2.19]$ & $1.53[-.71,3.78]$ & $1.00[.51,1.49]$ & $.56[-.81,1.92]$ & $1.34[-.15,2.83]$ & $.53[.21, .84]$ \\
\hline
\end{tabular}

Note: $\mathrm{A}=$ genetic variation, $\mathrm{C}=$ shared environmental variation, $\mathrm{E}=$ unique environmental variation. $95 \%$ confidence intervals are in brackets. Parameter estimates that are statistically significant at $\mathrm{p}<.05$ are denoted with bold. 


\section{Appendix 2}

Figures of Results

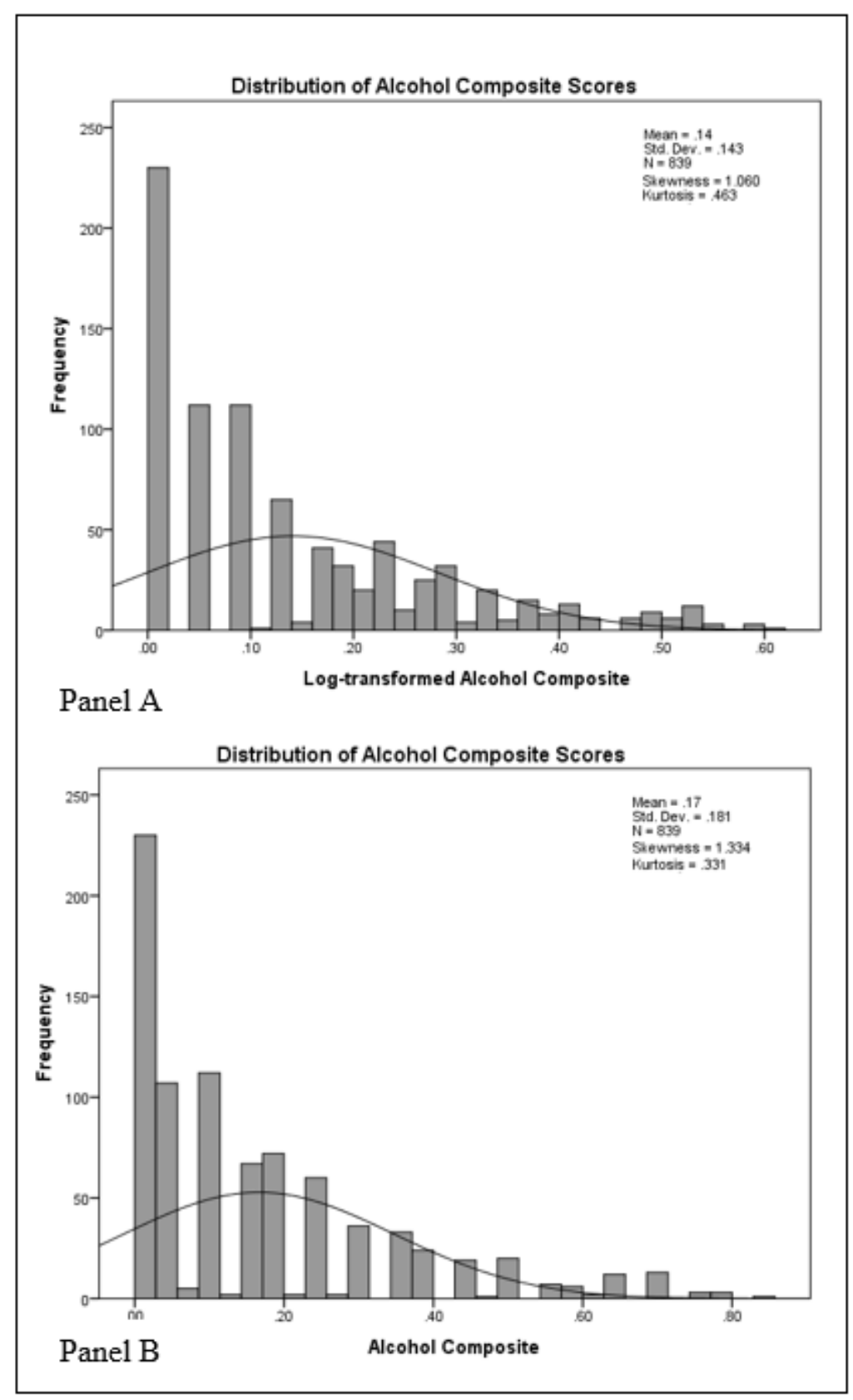

Figure 1. Distribution of the alcohol composite variable. Panel A shows the distribution of the alcohol composite variable following log-transformation while Panel B shows the distribution prior to transformation. 


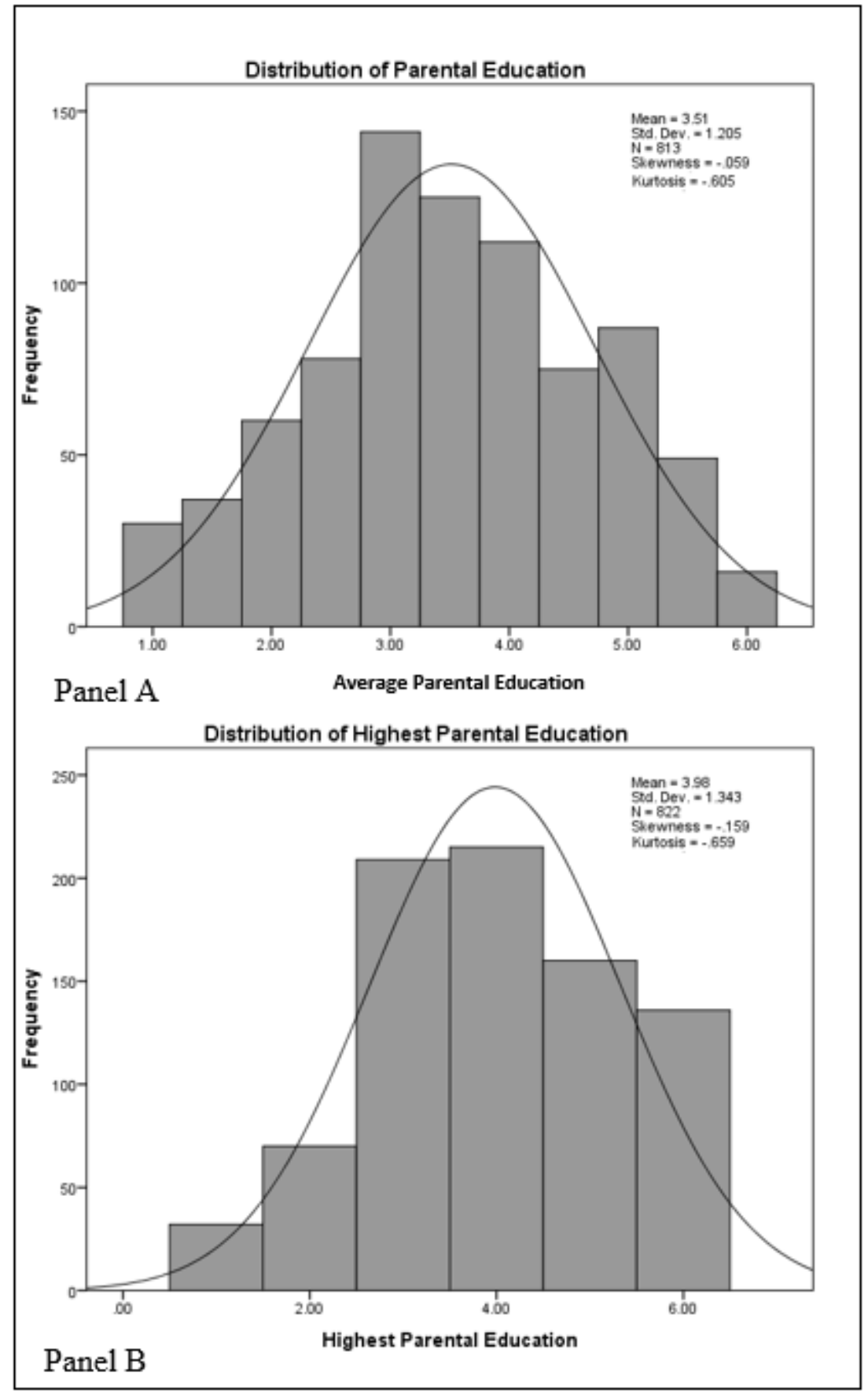

Figure 2. Distribution of the parental education variables. Panel A shows the distribution of the average parental education variable, while Panel B shows the distribution of the highest parental education variable. 


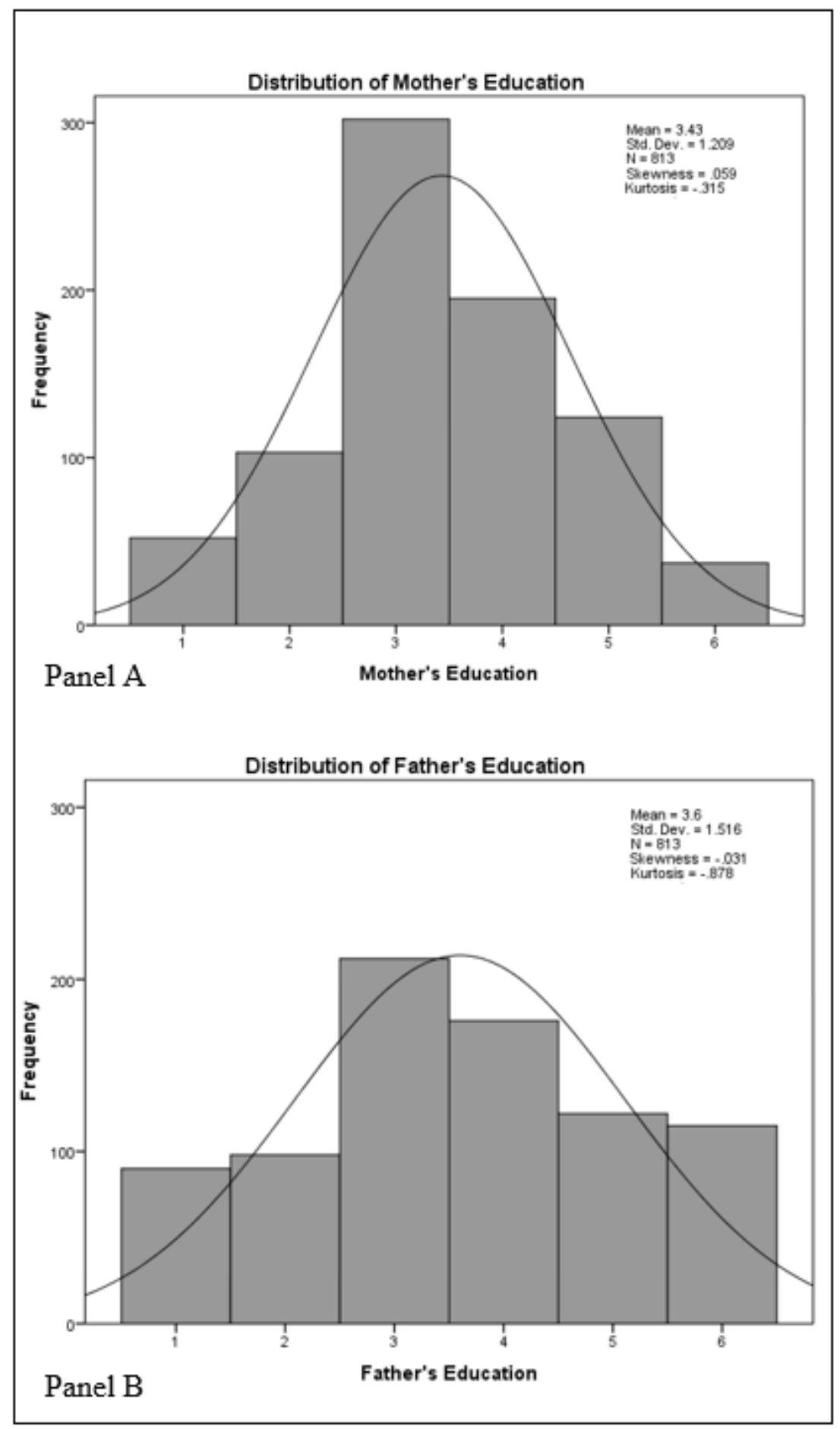

Figure 3. Distribution of parental education levels. Panel A shows the distribution of maternal education levels, while Panel B shows the distribution of paternal education levels among the sample. 


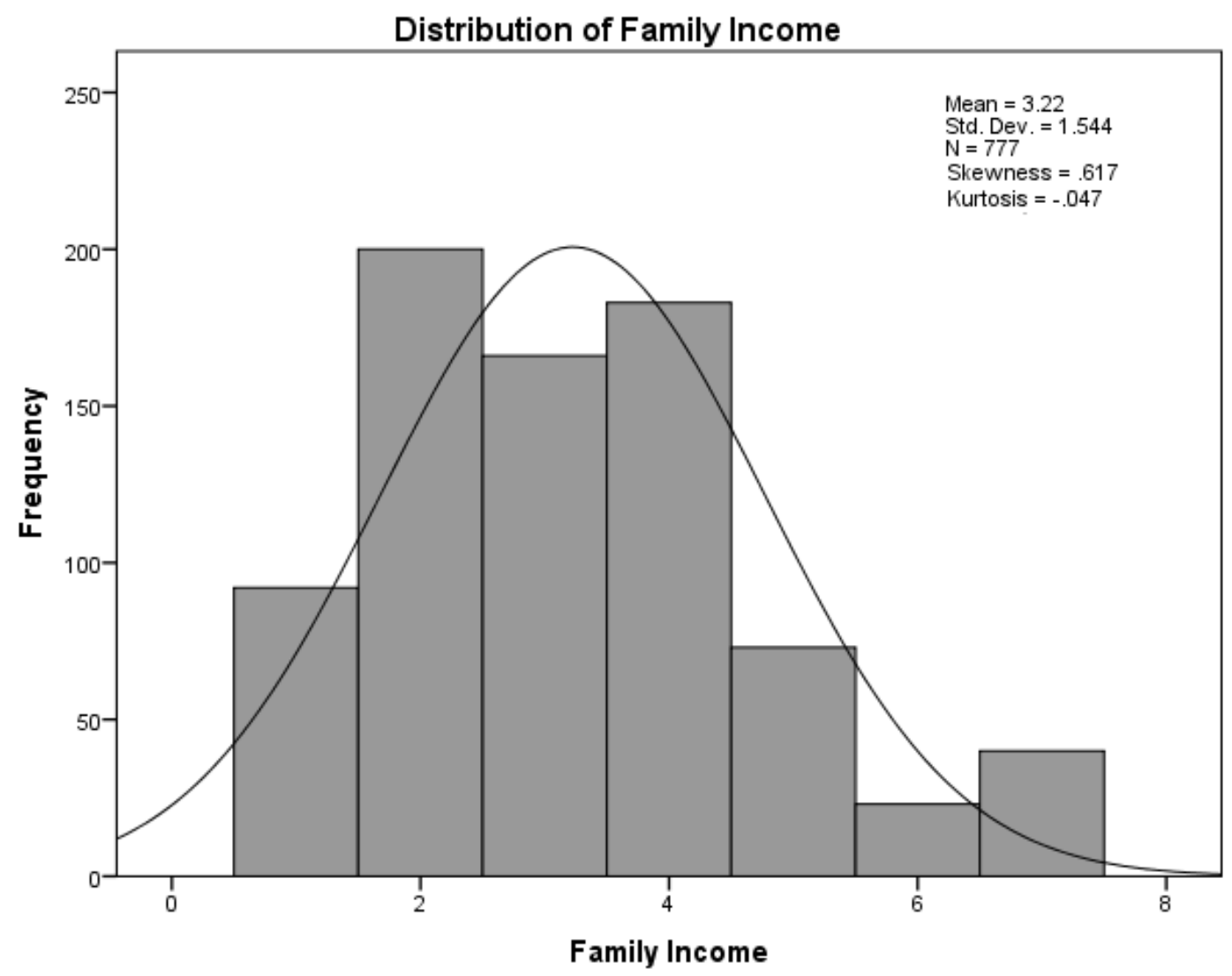

Figure 4. Distribution of the annual family income variable. 


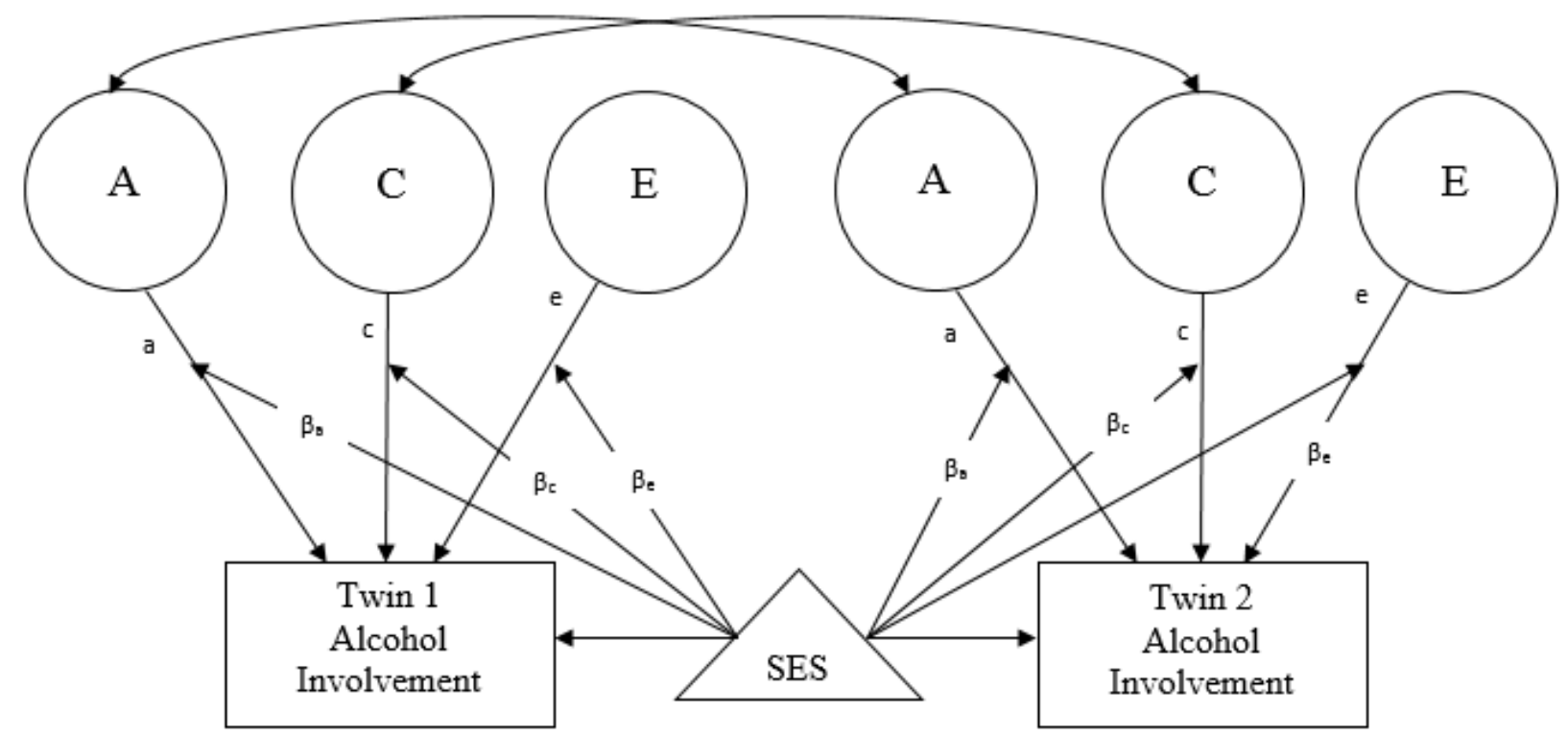

Figure 5. Path diagram for the full moderation model. $\mathrm{A}=$ additive genetic influences, $\mathrm{C}$ $=$ shared environmental influences, $\mathrm{E}=$ unique environmental influences, $\mathrm{MZ}=$ monozygotic twins, $\mathrm{DZ}=$ dizygotic twins. 


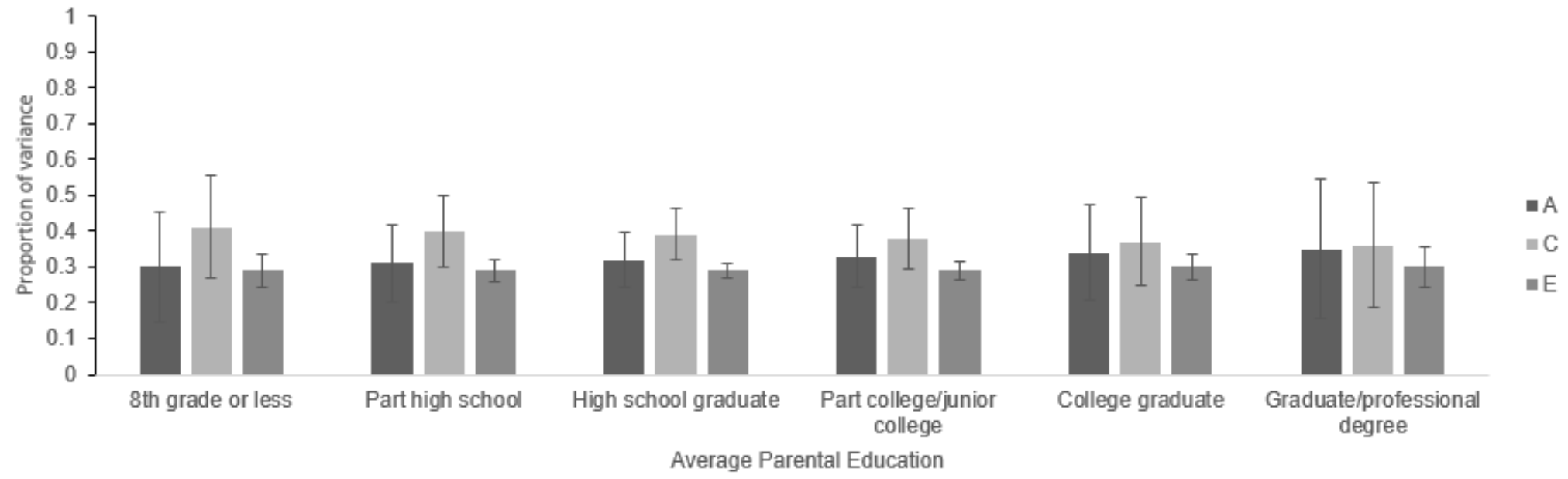

Figure 6. Results from the full sample G x E model for average parental education. This model showed no evidence of significant moderation. 
SOCIOECONOMIC STATUS AND ALCOHOL INVOLVEMENT

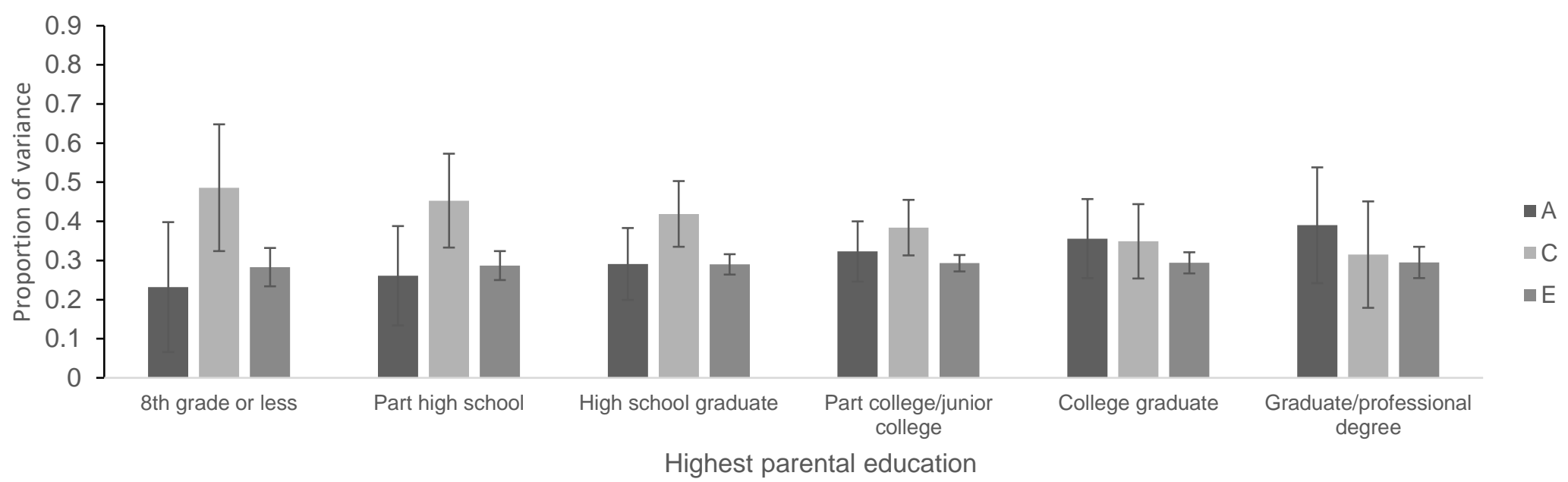

Figure 7. Results from the full sample G x E model for highest parental education. This model showed no evidence of significant moderation. 


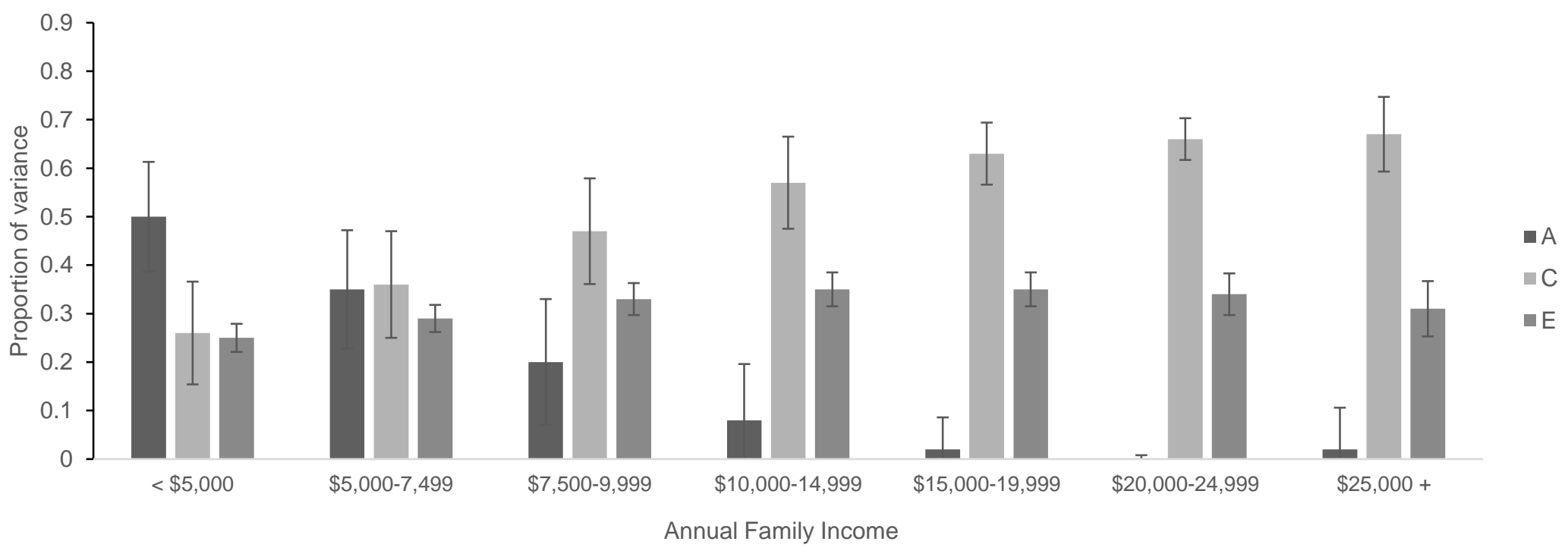

Figure 8. Results from the full sample G x E model for family income. This model showed evidence of significant moderation of the $\mathrm{A}, \mathrm{C}$, and $\mathrm{E}$ components of variance. 


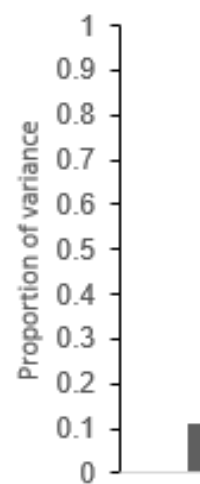

8th grade or less

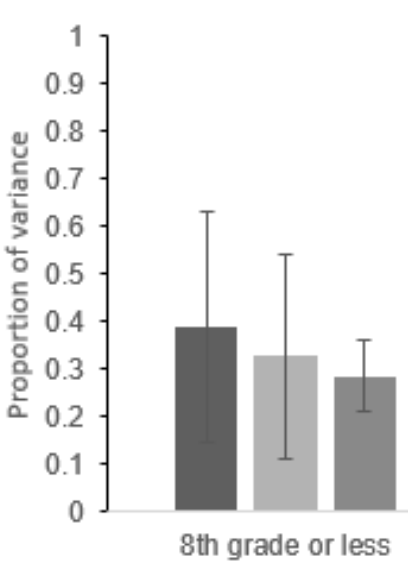

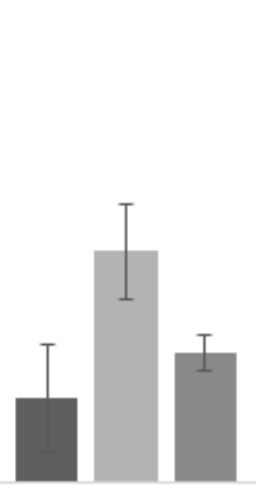

Part high school

Females

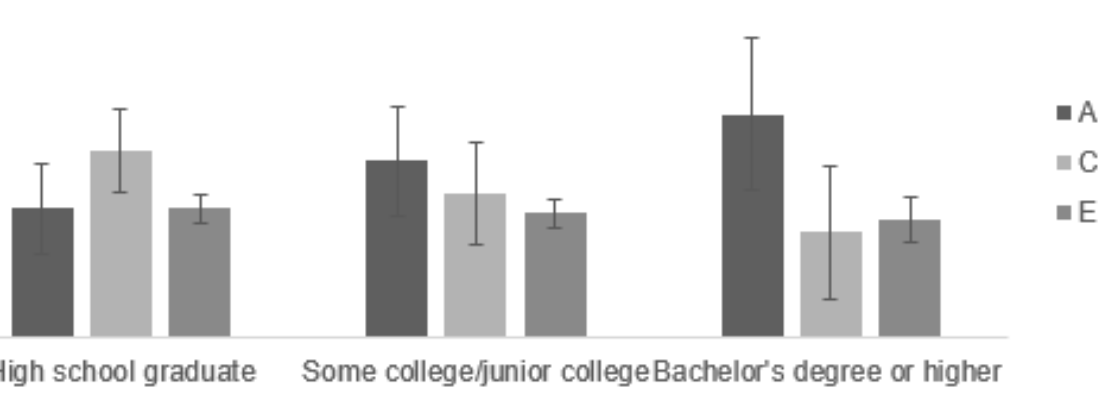

Average Parental Education

Males
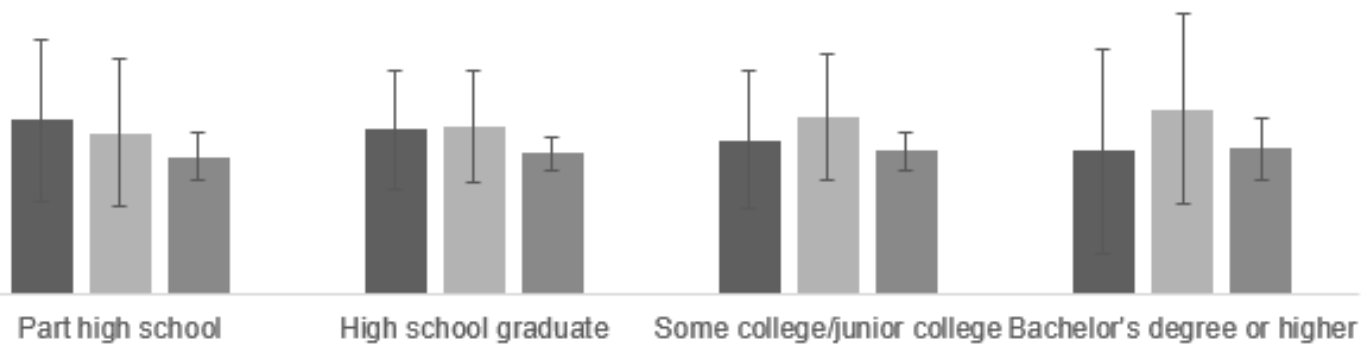

Average Parental Education

- $\mathrm{A}$

$\mathrm{C}$

E

Figure 9. Results from the sex-specific GxE model for average parental education. These models did not show evidence of significant moderation. 

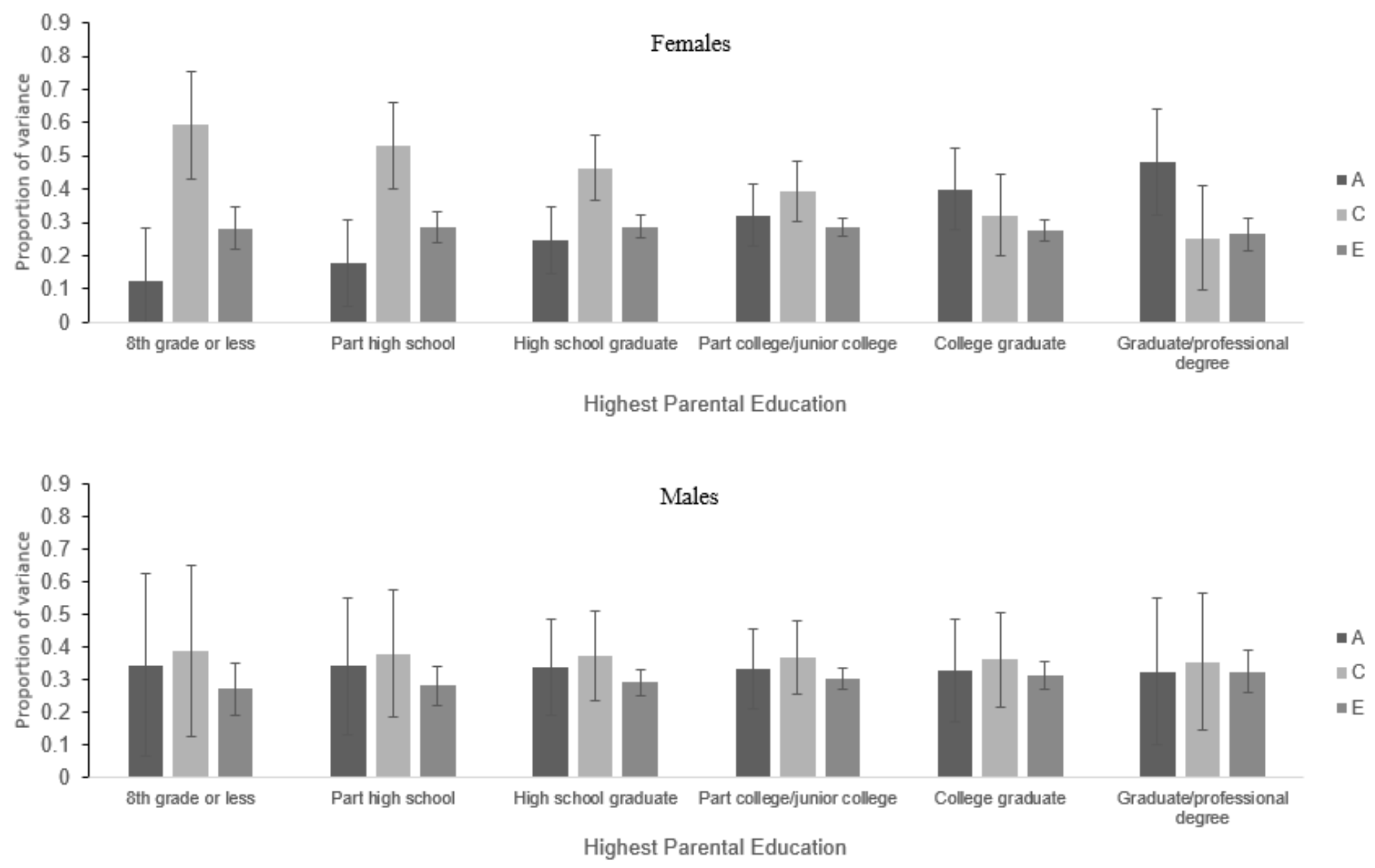

Figure 10. Results from the sex-specific GxE model for highest parental education. These models did not show evidence of significant moderation. 

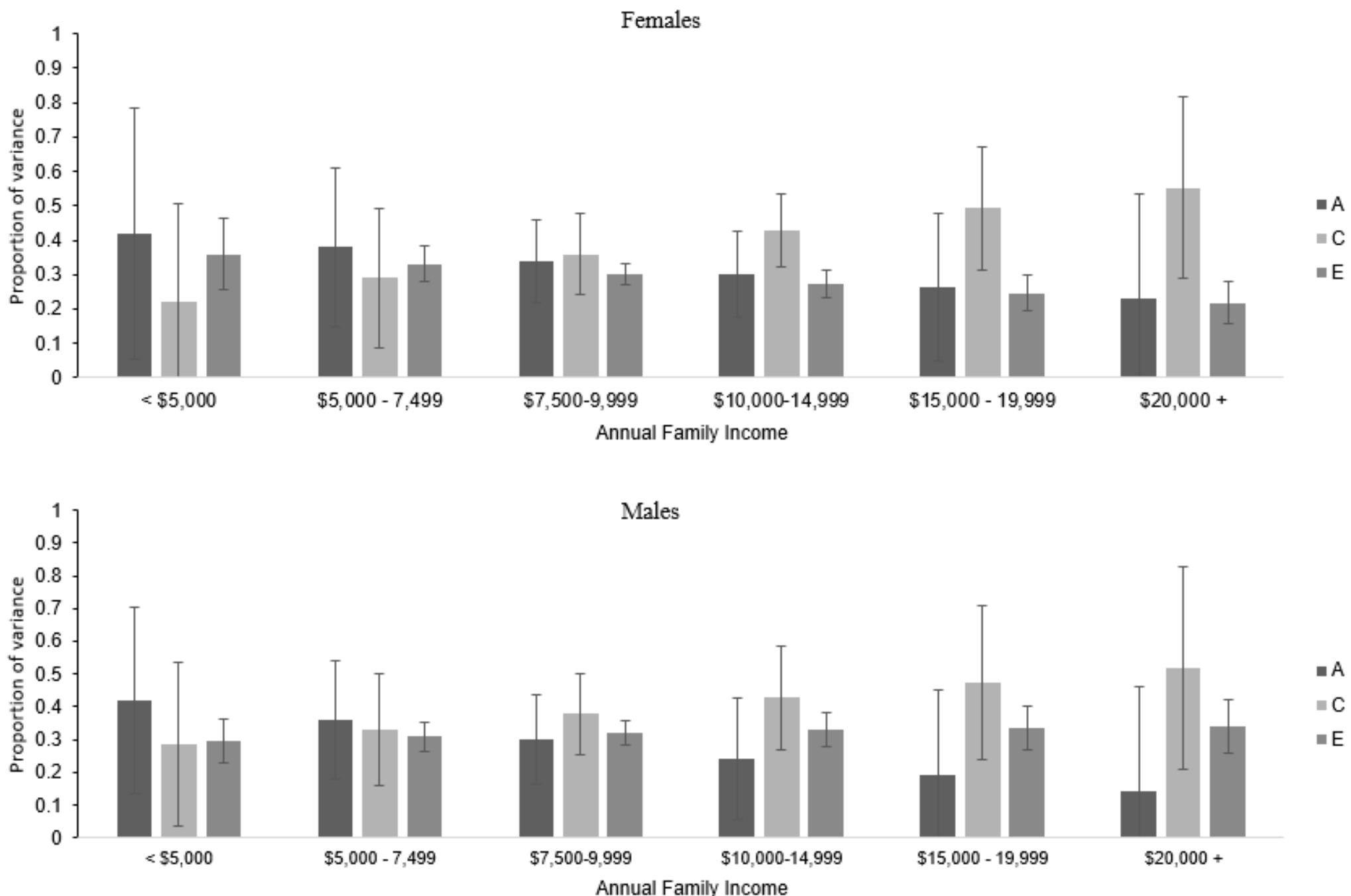

Figure 11. Results from the sex-specific G x E model for family income. These models did not show evidence of significant moderation. 


\section{Appendix 3}

\section{Summary of Models Tested}

Summary of models tested using the log-transformed alcohol composite

\begin{tabular}{|c|c|c|c|}
\hline \multicolumn{4}{|c|}{ Full Sample Analyses } \\
\hline Moderator (\# of levels) & $\chi^{2}$ & $\mathrm{df}$ & $\mathrm{p}$-value \\
\hline Family Income (7) & 21.86 & 3 & $.0001^{*}$ \\
\hline Family Income (6) & 1.97 & 3 & .58 \\
\hline Family Income (5) & 1.73 & 3 & .63 \\
\hline Avg. Parental Education (6) & 0.42 & 3 & .94 \\
\hline Avg. Parental Education (5) & .96 & 3 & .81 \\
\hline Avg. Parental Education (4) & .58 & 3 & .90 \\
\hline Paternal Education & .53 & 3 & .91 \\
\hline Maternal Education & .74 & 3 & .86 \\
\hline Highest Parental Education & .65 & 3 & .89 \\
\hline \multicolumn{4}{|c|}{ Sex-specific Analyses: Tests of Moderation among Males } \\
\hline Moderator (\# of levels) & $\chi^{2}$ & $\mathrm{df}$ & p-value \\
\hline Family Income (7) & 4.04 & 3 & .26 \\
\hline Family Income (6) & .23 & 3 & .97 \\
\hline Family Income (5) & .06 & 3 & .99 \\
\hline Avg. Parental Education (6) & 2.58 & 3 & .46 \\
\hline Avg. Parental Education (5) & 2.20 & 3 & .53 \\
\hline Avg. Parental Education (4) & 2.44 & 3 & .49 \\
\hline Paternal Education & 1.37 & 3 & .71 \\
\hline Maternal Education & 1.45 & 3 & 69 \\
\hline Highest Parental Education & .57 & 3 & .90 \\
\hline \multicolumn{4}{|c|}{ Sex-specific Analyses: Tests of Moderation among Females } \\
\hline Moderator (\# of levels) & $\chi^{2}$ & df & p-value \\
\hline Family Income (7) & 5.49 & 3 & .14 \\
\hline Family Income (6) & 3.95 & 3 & .27 \\
\hline Family Income (5) & 5.00 & 3 & .17 \\
\hline Avg. Parental Education (6) & 2.20 & 3 & .53 \\
\hline Avg. Parental Education (5) & 2.59 & 3 & .46 \\
\hline Avg. Parental Education (4) & 1.84 & 3 & .61 \\
\hline Paternal Education & 1.29 & 3 & .73 \\
\hline Maternal Education & 1.80 & 3 & .62 \\
\hline Highest Parental Education & 1.34 & 3 & .72 \\
\hline
\end{tabular}

Note: $\chi 2$ value represents a Wald test that all moderation parameters are zero. * denote significance. 
Summary of models tested using the untransformed alcohol composite

\begin{tabular}{|c|c|c|c|}
\hline \multicolumn{4}{|c|}{ Full Sample Analyses } \\
\hline Moderator (\# of levels) & $\chi^{2}$ & df & p-value \\
\hline Family Income (7) & 34.32 & 3 & $<.0001 *$ \\
\hline Family Income (6) & 68.09 & 3 & $<.0001 *$ \\
\hline Family Income (5) & 2.83 & 3 & .42 \\
\hline Avg. Parental Education (6) & .58 & 3 & .90 \\
\hline Avg. Parental Education (5) & 1.06 & 3 & .79 \\
\hline Avg. Parental Education (4) & .84 & 3 & .84 \\
\hline Paternal Education & 1.72 & 3 & .63 \\
\hline Maternal Education & 1.14 & 3 & .77 \\
\hline Highest Parental Education & .57 & 3 & .90 \\
\hline \multicolumn{4}{|c|}{ Sex-specific Analyses: Tests of Moderation among Males } \\
\hline Moderator (\# of levels) & $\chi^{2}$ & df & p-value \\
\hline Family Income (7) & 6.31 & 3 & .10 \\
\hline Family Income (6) & 1.17 & 3 & .76 \\
\hline Family Income (5) & .33 & 3 & .95 \\
\hline Avg. Parental Education (6) & 3.63 & 3 & .46 \\
\hline Avg. Parental Education (5) & 3.10 & 3 & .38 \\
\hline Avg. Parental Education (4) & 3.45 & 3 & .33 \\
\hline Paternal Education & 2.55 & 3 & .47 \\
\hline Maternal Education & 1.46 & 3 & 69 \\
\hline Highest Parental Education & .69 & 3 & .88 \\
\hline \multicolumn{4}{|c|}{ Sex-specific Analyses: Tests of Moderation among Females } \\
\hline Moderator (\# of levels) & $\chi^{2}$ & $\mathrm{df}$ & p-value \\
\hline Family Income (7) & 7.33 & 3 & .06 \\
\hline Family Income (6) & 4.90 & 3 & .18 \\
\hline Family Income (5) & 6.86 & 3 & .08 \\
\hline Avg. Parental Education (6) & 2.85 & 3 & .42 \\
\hline Avg. Parental Education (5) & 3.40 & 3 & .33 \\
\hline Avg. Parental Education (4) & 2.67 & 3 & .44 \\
\hline Paternal Education & .82 & 3 & .84 \\
\hline Maternal Education & 2.56 & 3 & .47 \\
\hline Highest Parental Education & 1.32 & 3 & .73 \\
\hline
\end{tabular}

Note: $\chi 2$ value is the result of a Wald test that all moderation parameters are zero. * denote significance. 